Supporting Information of

\title{
Acceleration and Deceleration Factors on the Hydrolysis Reaction of 4,6-O-Benzylidene Acetal Group
}

Yuta Maki, ${ }^{1,2 *}$ Kota Nomura, ${ }^{1,2}$ Ryo Okamoto, ${ }^{1,2}$ Masayuki Izumi, ${ }^{1}$ Yasuhisa Mizutani, ${ }^{1}$ and Yasuhiro Kajihara ${ }^{1,2 *}$

1. Department of Chemistry, Graduate School of Science, Osaka University, 1-1

Machikaneyama, Toyonaka, Osaka 560-0043, Japan

2. Project Research Center for Fundamental Sciences, Graduate School of Science, Osaka University, 1-1 Machikaneyama, Toyonaka, Osaka 560-0043, Japan

*Corresponding authors:

Yuta Maki: makiyt11@chem.sci.osaka-u.ac.jp

Yasuhiro Kajihara: kajihara@chem.sci.osaka-u.ac.jp 


\section{Table of Contents}

1. Summary of obtained data

1.1 Data for non-acetylated substrates at $10{ }^{\circ} \mathrm{C}$

1.2 Data for di-acetylated substrates at $10{ }^{\circ} \mathrm{C}$

1.3 Data for non-acetylated substrates at $23^{\circ} \mathrm{C}$

1.4 Data for di-acetylated substrates at $23{ }^{\circ} \mathrm{C}$

1.5 Data for non-acetylated substrates at $28{ }^{\circ} \mathrm{C}$

1.6 Data for di-acetylated substrates at $28{ }^{\circ} \mathrm{C}$

1.7 Data for non-acetylated substrates at $33{ }^{\circ} \mathrm{C}$

S28

1.8 Data for di-acetylated substrates at $33{ }^{\circ} \mathrm{C}$

1.9 List of hydrolysis velocity $(\mathrm{k}), \ln (\mathrm{k})$, and $\ln (\mathrm{k} / \mathrm{T})$

1.10 Arrhenius plot

1.11 Eyring plot

1.12 Calculation of $\Delta \mathrm{G}^{ \pm}$based on the Eyring equation

2. NMR Data

$2.1{ }^{1} \mathrm{H},{ }^{13} \mathrm{C}$ NMR spectra of compound 1

S45

$2.2{ }^{1} \mathrm{H},{ }^{13} \mathrm{C}$ NMR spectra of compound 2

S46

$2.3{ }^{1} \mathrm{H},{ }^{13} \mathrm{C}$ NMR spectra of compound 3

$2.4{ }^{1} \mathrm{H},{ }^{13} \mathrm{C}$ NMR spectra of compound 4

S48

$2.5{ }^{1} \mathrm{H},{ }^{13} \mathrm{C}$ NMR spectra of compound 5

S49

$2.6{ }^{1} \mathrm{H},{ }^{13} \mathrm{C}$ NMR spectra of compound 6 
1.1 Data for non-acetylated substrates $\mathbf{1 - 3}$ at $10{ }^{\circ} \mathrm{C}$
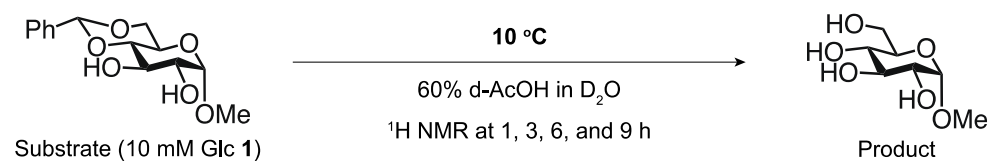

Scheme S1. Hydrolysis of 4,6-O-benzylidene acetal of Glc 1.

\begin{tabular}{|c|c|c|c|c|c|}
\hline & $\begin{array}{l}\text { Time point } \\
\text { [hour] }\end{array}$ & $\begin{array}{c}\int \mathrm{S} \\
\text { (Integral of substrate) }\end{array}$ & $\begin{array}{c}\int P \\
\text { (Integral of product) }\end{array}$ & $\int \mathbf{S} /\left(\int \mathbf{S}+\int \mathbf{P}\right)$ & $\ln \left[\int \mathbf{S} /\left(\int \mathbf{S}+\int \mathbf{P}\right)\right]$ \\
\hline \multirow[t]{4}{*}{ Glc $1 \# 1$} & 1 & 1 & 0.1304 & 0.885 & -0.123 \\
\hline & 3 & 1 & 0.2295 & 0.813 & -0.207 \\
\hline & 6 & 1 & 0.4127 & 0.708 & -0.346 \\
\hline & 9 & 1 & 0.6152 & 0.619 & -0.479 \\
\hline \multirow[t]{4}{*}{ Glc $1 \# 2$} & 1 & 1 & 0.0944 & 0.914 & -0.090 \\
\hline & 3 & 1 & 0.2163 & 0.822 & -0.196 \\
\hline & 6 & 1 & 0.4026 & 0.713 & -0.338 \\
\hline & 9 & 1 & 0.6053 & 0.623 & -0.473 \\
\hline \multirow[t]{4}{*}{ Glc $1 \# 3$} & 1 & 1 & 0.1197 & 0.893 & -0.113 \\
\hline & 3 & 1 & 0.2158 & 0.823 & -0.195 \\
\hline & 6 & 1 & 0.4255 & 0.702 & -0.355 \\
\hline & 9 & 1 & 0.6038 & 0.624 & -0.472 \\
\hline
\end{tabular}

Table S1. All experiments were conducted in triplicate. Glc 1 \#1 stands for the $1^{\text {st }}$ experiment using Glc 1 as a substrate, and ${ }^{1} \mathrm{H}$ NMR was measured at 1, 3, 6, and 9 hours. Integral of substrate $\left[\int \mathrm{S}\right]$ was set as 1 , and accordingly the integral of product $\left[\int \mathrm{P}\right]$ was obtained.

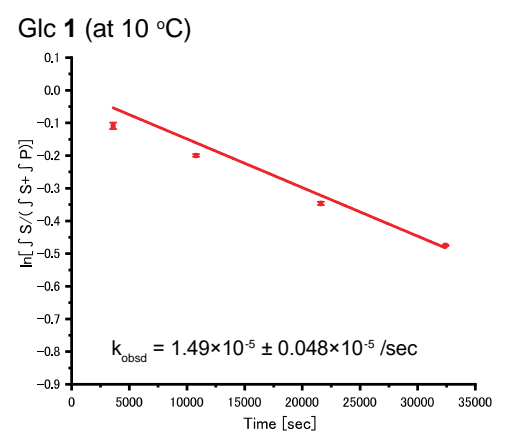


Figure S1. The values of $\ln \left[\int \mathrm{S} /\left(\int \mathrm{S}+\int \mathrm{P}\right)\right]$ obtained by three experiments were plotted as a function of time ( $\mathrm{sec})$, and the intercept was set at 0 . The value of $\mathrm{k}_{\mathrm{obsd}}$ was obtained by statistical analysis and the error bars are shown. In addition, the individual reaction rate constant $\left(\mathrm{k}_{\# 1}, \mathrm{k}_{\# 2}\right.$, and $\left.\mathrm{k}_{\# 3}[/ \mathrm{sec}]\right)$ was obtained from each experiment using Equation 1 by simple linear approximation, and the results are summarized in Table S25. The obtained values were used for following calculation of the Arrhenius and Eyring equations.
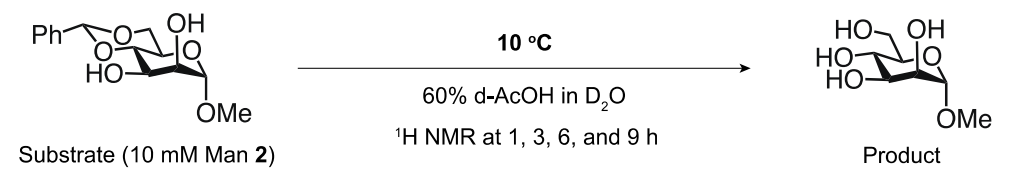

Scheme S2. Hydrolysis of 4,6-O-benzylidene acetal of Man 2.

\begin{tabular}{|c|c|c|c|c|c|}
\hline & $\begin{array}{l}\text { Time point } \\
\text { [hour] }\end{array}$ & $\begin{array}{c}\int \mathrm{S} \\
\text { (Integral of substrate) }\end{array}$ & $\begin{array}{c}\int \mathbf{P} \\
\text { (Integral of product) }\end{array}$ & $\int \mathbf{S} /\left(\int \mathbf{S}+\int \mathbf{P}\right)$ & $\ln \left[\int \mathbf{S} /\left(\int \mathbf{S}+\int \mathbf{P}\right)\right]$ \\
\hline \multirow[t]{4}{*}{ Man 2 \#1 } & 1 & 1 & 0.2008 & 0.833 & -0.183 \\
\hline & 3 & 1 & 0.3825 & 0.723 & -0.324 \\
\hline & 6 & 1 & 0.7085 & 0.585 & -0.536 \\
\hline & 9 & 1 & 1.1604 & 0.463 & -0.770 \\
\hline \multirow[t]{4}{*}{ Man 2 \#2 } & 1 & 1 & 0.1394 & 0.878 & -0.131 \\
\hline & 3 & 1 & 0.2988 & 0.770 & -0.261 \\
\hline & 6 & 1 & 0.6474 & 0.607 & -0.499 \\
\hline & 9 & 1 & 0.9959 & 0.501 & -0.691 \\
\hline \multirow[t]{4}{*}{ Man 2 \#3 } & 1 & 1 & 0.1702 & 0.855 & -0.157 \\
\hline & 3 & 1 & 0.3363 & 0.748 & -0.290 \\
\hline & 6 & 1 & 0.6470 & 0.607 & -0.499 \\
\hline & 9 & 1 & 1.0384 & 0.491 & -0.712 \\
\hline
\end{tabular}

Table S2. All experiments were conducted in triplicate. Man $2 \# 1$ stands for the $1^{\text {st }}$ experiment using Man 2 as a substrate, and ${ }^{1} \mathrm{H}$ NMR was measured at 1, 3, 6, and 9 hours. Integral of substrate $\left[\int \mathrm{S}\right]$ was set as 1 , and accordingly the integral of product $\left[\int \mathrm{P}\right]$ was obtained. 


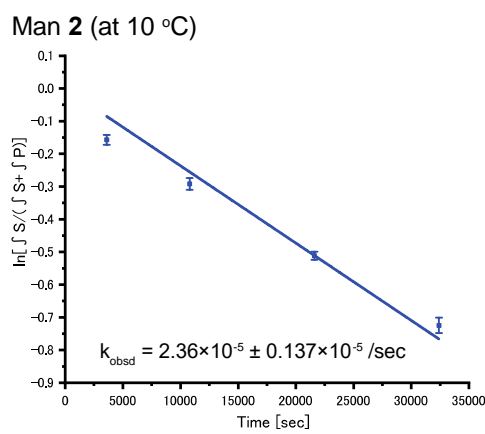

Figure S2. The values of $\ln \left[\int \mathrm{S} /\left(\int \mathrm{S}+\int \mathrm{P}\right)\right]$ obtained by three experiments were plotted as a function of time (sec), and the intercept was set at 0 . The value of $k_{\text {obsd }}$ was obtained by statistical analysis and the error bars are shown. In addition, the individual reaction rate constant $\left(\mathrm{k}_{\# 1}, \mathrm{k}_{\# 2}\right.$, and $\left.\mathrm{k}_{\# 3}[/ \mathrm{sec}]\right)$ was obtained from each experiment using Equation 1 by simple linear approximation, and the results are summarized in Table $\mathbf{S 2 5}$. The obtained values were used for following calculation of the Arrhenius and Eyring equations.

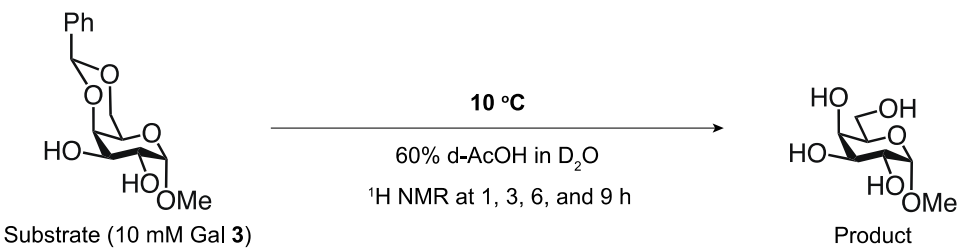

Scheme S3. Hydrolysis of 4,6-O-benzylidene acetal of Gal 3.

\begin{tabular}{|c|c|c|c|c|c|}
\hline & $\begin{array}{l}\text { Time point } \\
\text { [hour] }\end{array}$ & $\begin{array}{c}\int \mathrm{S} \\
\text { (Integral of substrate) }\end{array}$ & $\begin{array}{c}\int \mathbf{P} \\
\text { (Integral of product) }\end{array}$ & $\int \mathbf{S} /\left(\int \mathbf{S}+\int \mathbf{P}\right)$ & $\ln \left[\int \mathbf{S} /\left(\int \mathbf{S}+\int \mathbf{P}\right)\right]$ \\
\hline \multirow[t]{4}{*}{ Gal 3 \#1 } & 1 & 1 & 0.0333 & 0.968 & -0.0328 \\
\hline & 3 & 1 & 0.0419 & 0.960 & -0.0410 \\
\hline & 6 & 1 & 0.0736 & 0.931 & -0.0710 \\
\hline & 9 & 1 & 0.1000 & 0.909 & -0.0953 \\
\hline \multirow[t]{4}{*}{ Gal 3 \#2 } & 1 & 1 & 0.03 & 0.971 & -0.0296 \\
\hline & 3 & 1 & 0.0505 & 0.952 & -0.0493 \\
\hline & 6 & 1 & 0.0856 & 0.921 & -0.0821 \\
\hline & 9 & 1 & 0.0954 & 0.913 & -0.0911 \\
\hline
\end{tabular}




\begin{tabular}{|r|r|r|r|r|r|} 
Gal 3 \#3 & 1 & 1 & 0.0275 & 0.973 & -0.0271 \\
\cline { 2 - 6 } & 3 & 1 & 0.0530 & 0.950 & -0.0516 \\
\cline { 2 - 6 } & 6 & 1 & 0.0737 & 0.931 & -0.0711 \\
\hline & 1 & 0.0936 & 0.914 & -0.0895 \\
\hline
\end{tabular}

Table S3. All experiments were conducted in triplicate. Gal 3 \#1 stands for the $1^{\text {st }}$ experiment using Gal 3 as a substrate, and ${ }^{1} \mathrm{H}$ NMR was measured at 1, 3, 6, and 9 hours. Integral of substrate $\left[\int \mathrm{S}\right]$ was set as 1 , and accordingly the integral of product $\left[\int \mathrm{P}\right]$ was obtained.

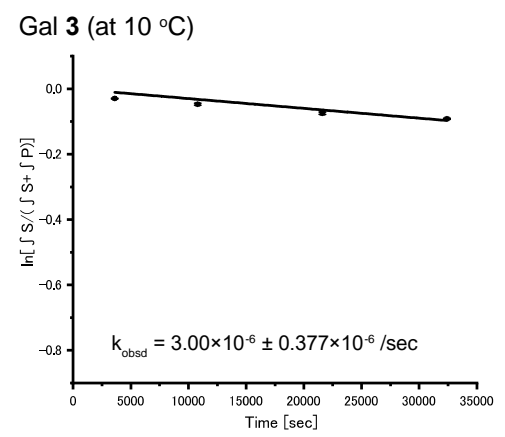

Figure S3. The values of $\ln \left[\int \mathrm{S} /\left(\int \mathrm{S}+\int \mathrm{P}\right)\right]$ obtained by three experiments were plotted as a function of time ( $\mathrm{sec}$ ), and the intercept was set at 0 . The value of $\mathrm{k}_{\mathrm{obsd}}$ was obtained by statistical analysis and the error bars are shown. In addition, the individual reaction rate constant $\left(\mathrm{k}_{\# 1}, \mathrm{k}_{\# 2}\right.$, and $\left.\mathrm{k}_{\# 3}[/ \mathrm{sec}]\right)$ was obtained from each experiment using Equation 1 by simple linear approximation, and the results are summarized in Table S25. The obtained values were used for following calculation of the Arrhenius and Eyring equations. 
1.2 Data for di-acetylated substrates $4-6$ at $10{ }^{\circ} \mathrm{C}$
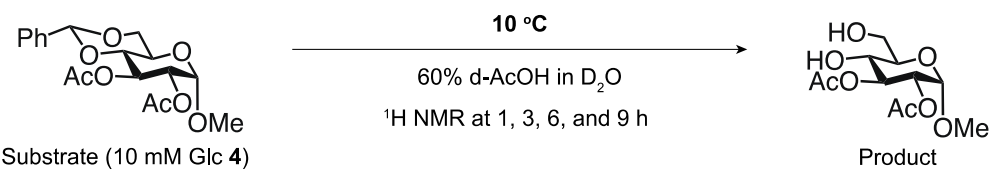

Substrate (10 mM Glc 4)

Product

Scheme S4. Hydrolysis of 4,6-O-benzylidene acetal of Glc 4.

\begin{tabular}{|l|l|l|l|l|l|}
\hline & $\begin{array}{l}\text { Time point } \\
\text { [hour] }\end{array}$ & $\begin{array}{l}\text { S S } \\
\text { (Integral of substrate) }\end{array}$ & $\begin{array}{l}\text { S P } \\
\text { (Integral of product) }\end{array}$ & S S/ ( S S S P) & In [ S S/ S S + S P)] \\
\hline Glc 4 \#1 & 1 & 3 & 0.1748 & 0.9449 & \\
\hline & 3 & 3 & 0.3298 & 0.9010 & -0.0566 \\
\hline & 6 & 3 & 0.5646 & 0.8416 & -0.1043 \\
\hline Glc 4 \#2 & 1 & 3 & 0.8191 & 0.7855 & -0.1724 \\
\hline & 3 & 3 & 0.3829 & 0.8868 & -0.2414 \\
\hline & 6 & 3 & 0.4145 & 0.8786 & -0.1201 \\
\hline & 9 & 3 & 0.6339 & 0.8256 & -0.1294 \\
\hline Glc 4 \#3 & 1 & 3 & 0.8523 & 0.7788 & -0.1917 \\
\hline & 3 & 3 & 0.1658 & 0.9476 & -0.2501 \\
\hline & 6 & 3 & 0.3416 & 0.8978 & -0.0538 \\
\hline & 9 & 3 & 0.5577 & 0.8432 & -0.1078 \\
\hline
\end{tabular}

Table S4. All experiments were conducted in triplicate. Glc 4 \#1 stands for the $1^{\text {st }}$ experiment using Glc 4 as a substrate, and ${ }^{1} \mathrm{H}$ NMR was measured at 1, 3, 6, and 9 hours. Integral of substrate $\left[\int \mathrm{S}\right]$ was set as 1 , and accordingly the integral of product $\left[\int \mathrm{P}\right]$ was obtained.

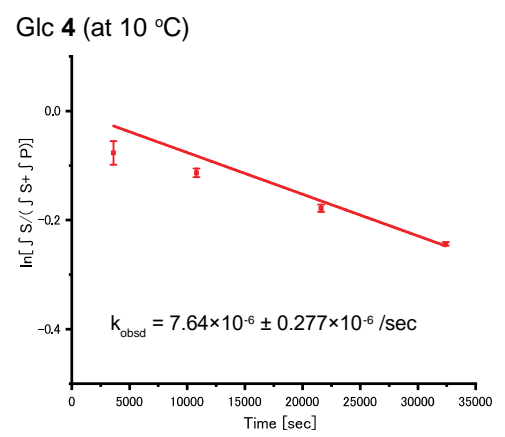


Figure S4. The values of $\ln \left[\int \mathrm{S} /\left(\int \mathrm{S}+\int \mathrm{P}\right)\right]$ obtained by three experiments were plotted as a function of time ( $\mathrm{sec})$, and the intercept was set at 0 . The value of $\mathrm{k}_{\mathrm{obsd}}$ was obtained by statistical analysis and the error bars are shown. In addition, the individual reaction rate constant $\left(\mathrm{k}_{\# 1}, \mathrm{k}_{\# 2}\right.$, and $\left.\mathrm{k}_{\# 3}[/ \mathrm{sec}]\right)$ was obtained from each experiment using Equation 1 by simple linear approximation, and the results are summarized in Table S25. The obtained values were used for following calculation of the Arrhenius and Eyring equations.
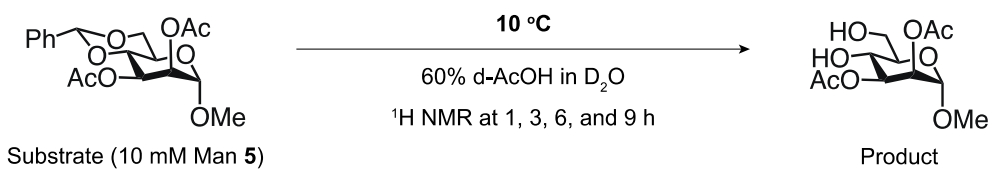

Scheme S5. Hydrolysis of 4,6-O-benzylidene acetal of Man 5.

\begin{tabular}{|c|c|c|c|c|c|}
\hline & $\begin{array}{l}\text { Time point } \\
\text { [hour] }\end{array}$ & $\begin{array}{c}\int \mathrm{S} \\
\text { (Integral of substrate) }\end{array}$ & $\begin{array}{c}\int P \\
\text { (Integral of product) }\end{array}$ & $\int \mathbf{S} /\left(\int \mathbf{S}+\int \mathbf{P}\right)$ & $\ln \left[\int \mathbf{S} /\left(\int \mathbf{S}+\int \mathbf{P}\right)\right]$ \\
\hline \multirow[t]{4}{*}{ Man 5 \#1 } & 1 & 3 & 0.1261 & 0.9597 & -0.0412 \\
\hline & 3 & 3 & 0.2745 & 0.9162 & -0.0876 \\
\hline & 6 & 3 & 0.4499 & 0.8696 & -0.1397 \\
\hline & 9 & 3 & 0.6469 & 0.8226 & -0.1953 \\
\hline \multirow[t]{4}{*}{ Man 5 \#2 } & 1 & 3 & 0.1452 & 0.9538 & -0.0473 \\
\hline & 3 & 3 & 0.2666 & 0.9184 & -0.0851 \\
\hline & 6 & 3 & 0.5083 & 0.8551 & -0.1565 \\
\hline & 9 & 3 & 0.6994 & 0.8109 & -0.2096 \\
\hline \multirow[t]{4}{*}{ Man 5 \#3 } & 1 & 3 & 0.1394 & 0.9556 & -0.0454 \\
\hline & 3 & 3 & 0.2632 & 0.9193 & -0.0841 \\
\hline & 6 & 3 & 0.4625 & 0.8664 & -0.1434 \\
\hline & 9 & 3 & 0.6691 & 0.8176 & -0.2013 \\
\hline
\end{tabular}

Table S5. All experiments were conducted in triplicate. Man $5 \# 1$ stands for the $1^{\text {st }}$ experiment using Man 5 as a substrate, and ${ }^{1} \mathrm{H}$ NMR was measured at 1, 3, 6, and 9 hours. Integral of substrate $\left[\int \mathrm{S}\right]$ was set as 1 , and accordingly the integral of product $\left[\int \mathrm{P}\right]$ was obtained. 


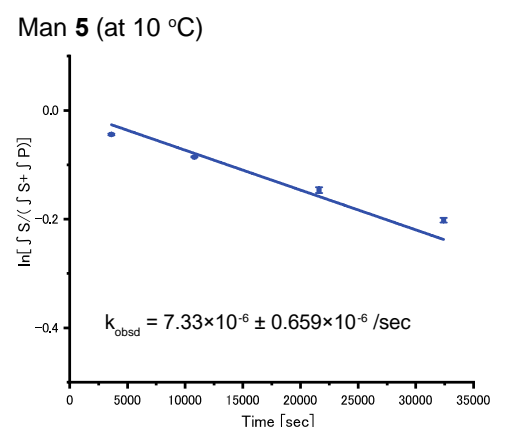

Figure S5. The values of $\ln \left[\int \mathrm{S} /\left(\int \mathrm{S}+\int \mathrm{P}\right)\right]$ obtained by three experiments were plotted as a function of time (sec), and the intercept was set at 0 . The value of $k_{\text {obsd }}$ was obtained by statistical analysis and the error bars are shown. In addition, the individual reaction rate constant $\left(\mathrm{k}_{\# 1}, \mathrm{k}_{\# 2}\right.$, and $\left.\mathrm{k}_{\# 3}[/ \mathrm{sec}]\right)$ was obtained from each experiment using Equation 1 by simple linear approximation, and the results are summarized in Table $\mathbf{S 2 5}$. The obtained values were used for following calculation of the Arrhenius and Eyring equations.

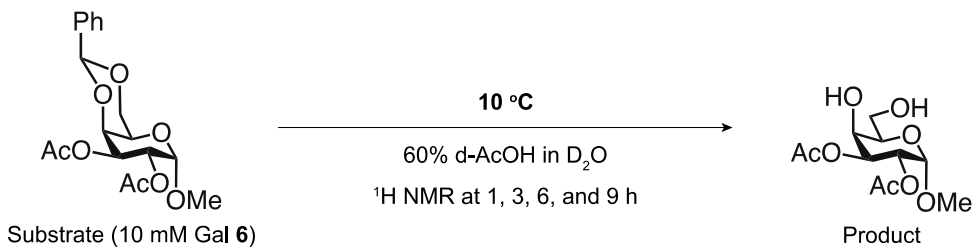

Scheme S6. Hydrolysis of 4,6-O-benzylidene acetal of Gal 6.

\begin{tabular}{|c|c|c|c|c|c|}
\hline & $\begin{array}{l}\text { Time point } \\
\text { [hour] }\end{array}$ & $\begin{array}{c}\int \mathbf{S} \\
\text { (Integral of substrate) }\end{array}$ & $\begin{array}{c}\int \mathrm{P} \\
\text { (Integral of product) }\end{array}$ & $\int \mathbf{S} /\left(\int \mathbf{S}+\int \mathbf{P}\right)$ & $\ln \left[\int \mathbf{S} /\left(\int \mathbf{S}+\int \mathbf{P}\right)\right]$ \\
\hline \multirow[t]{4}{*}{ Gal 6 \#1 } & 1 & 3 & 0.063 & 0.9794 & -0.0208 \\
\hline & 3 & 3 & 0.0878 & 0.9716 & -0.0288 \\
\hline & 6 & 3 & 0.1215 & 0.9611 & -0.0397 \\
\hline & 9 & 3 & 0.1441 & 0.9542 & -0.0469 \\
\hline \multirow[t]{4}{*}{ Gal 6 \#2 } & 1 & 3 & 0.0649 & 0.9788 & -0.0214 \\
\hline & 3 & 3 & 0.1345 & 0.9571 & -0.0439 \\
\hline & 6 & 3 & 0.14 & 0.9554 & -0.0456 \\
\hline & 9 & 3 & 0.2683 & 0.9179 & -0.0857 \\
\hline
\end{tabular}




\begin{tabular}{|l|r|r|r|r|r|} 
Gal 6 \#3 & 1 & 3 & 0.0437 & 0.9856 & -0.0145 \\
\cline { 2 - 6 } & 3 & 3 & 0.0694 & 0.9774 & -0.0229 \\
\cline { 2 - 6 } & 6 & 3 & 0.1118 & 0.9641 & -0.0366 \\
\hline & 9 & 3 & 0.1533 & 0.9514 & -0.0498 \\
\hline
\end{tabular}

Table S6. All experiments were conducted in triplicate. Gal 6 \#1 stands for the $1^{\text {st }}$ experiment using Gal 6 as a substrate, and ${ }^{1} \mathrm{H}$ NMR was measured at 1, 3, 6, and 9 hours. Integral of substrate $\left[\int \mathrm{S}\right]$ was set as 1 , and accordingly the integral of product $\left[\int \mathrm{P}\right]$ was obtained.

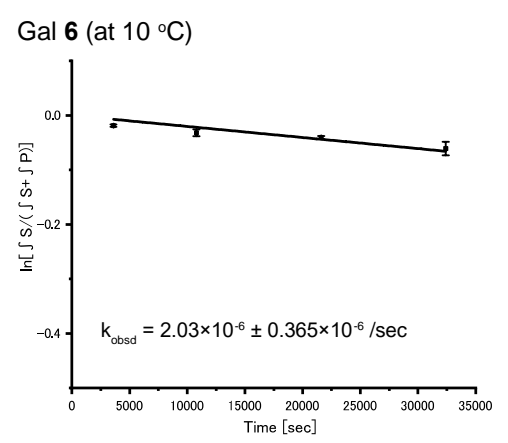

Figure S6. The values of $\ln \left[\int \mathrm{S} /\left(\int \mathrm{S}+\int \mathrm{P}\right)\right]$ obtained by three experiments were plotted as a function of time ( $\mathrm{sec}$ ), and the intercept was set at 0 . The value of $\mathrm{k}_{\mathrm{obsd}}$ was obtained by statistical analysis and the error bars are shown. In addition, the individual reaction rate constant $\left(\mathrm{k}_{\# 1}, \mathrm{k}_{\# 2}\right.$, and $\left.\mathrm{k}_{\# 3}[/ \mathrm{sec}]\right)$ was obtained from each experiment using Equation 1 by simple linear approximation, and the results are summarized in Table $\mathbf{S 2 5}$. The obtained values were used for following calculation of the Arrhenius and Eyring equations. 
1.3 Data for non-acetylated substrates $\mathbf{1 - 3}$ at $23{ }^{\circ} \mathrm{C}$
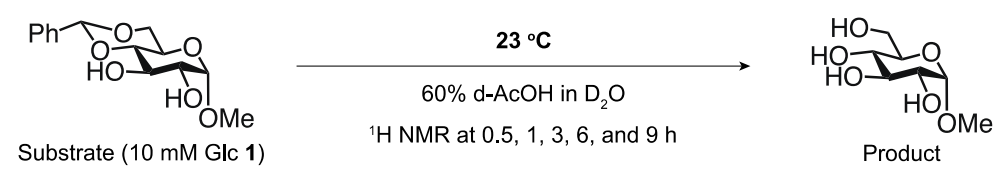

Scheme S7. Hydrolysis of 4,6-O-benzylidene acetal of Glc 1.

\begin{tabular}{|c|c|c|c|c|c|}
\hline & $\begin{array}{l}\text { Time point } \\
\text { [hour] }\end{array}$ & $\begin{array}{c}\int \mathrm{S} \\
\text { (Integral of } \\
\text { substrate) }\end{array}$ & $\begin{array}{c}\quad \int \mathrm{P} \\
\text { (Integral of } \\
\text { product) }\end{array}$ & $\int \mathbf{S} /\left(\int \mathbf{S}+\int \mathbf{P}\right)$ & $\ln \left[\int \mathbf{S} /\left(\int \mathbf{S}+\int \mathbf{P}\right)\right]$ \\
\hline \multirow[t]{5}{*}{ Glc 1 \#1 } & 0.5 & 1 & 0.0629 & 0.9408 & -0.0610 \\
\hline & 1 & 1 & 0.1803 & 0.8472 & -0.1658 \\
\hline & 3 & 1 & 0.8115 & 0.5520 & -0.5942 \\
\hline & 6 & 1 & 2.4765 & 0.2876 & -1.2460 \\
\hline & 9 & 1 & 5.4814 & 0.1543 & -1.8689 \\
\hline \multirow[t]{5}{*}{ Glc $1 \# 2$} & 0.5 & 1 & 0.1309 & 0.8843 & -0.1230 \\
\hline & 1 & 1 & 0.2602 & 0.7935 & -0.2313 \\
\hline & 3 & 1 & 0.9489 & 0.5131 & -0.6673 \\
\hline & 6 & 1 & 2.7253 & 0.2684 & -1.3151 \\
\hline & 9 & 1 & 5.6812 & 0.1497 & -1.8993 \\
\hline \multirow[t]{5}{*}{ Glc 1 \#3 } & 0.5 & 1 & 0.1563 & 0.8648 & -0.1452 \\
\hline & 1 & 1 & 0.2881 & 0.7763 & -0.2532 \\
\hline & 3 & 1 & 1.0957 & 0.4772 & -0.7399 \\
\hline & 6 & 1 & 3.0669 & 0.2459 & -1.4029 \\
\hline & 9 & 1 & 4.9524 & 0.1680 & -1.7838 \\
\hline
\end{tabular}

Table S7. All experiments were conducted in triplicate. Glc 1 \#1 stands for the $1^{\text {st }}$ experiment using Glc 1 as a substrate, and ${ }^{1} \mathrm{H}$ NMR was measured at $0.5,1,3,6$, and 9 hours. Integral of substrate $\left[\int \mathrm{S}\right]$ was set as 1 , and accordingly the integral of product $\left[\int \mathrm{P}\right]$ was obtained. 


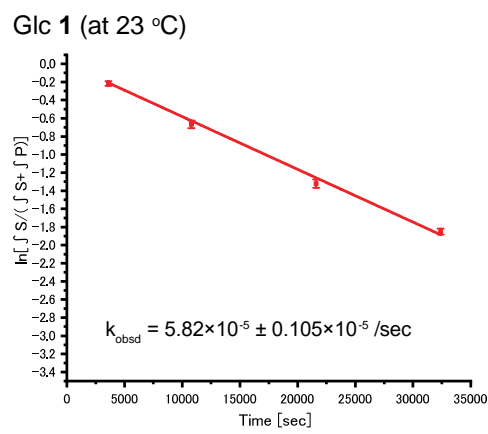

Figure S7. The values of $\ln \left[\int \mathrm{S} /\left(\int \mathrm{S}+\int \mathrm{P}\right)\right]$ obtained by three experiments were plotted as a function of time (sec), and the intercept was set at 0 . The value of $k_{\text {obsd }}$ was obtained by statistical analysis and the error bars are shown. In addition, the individual reaction rate constant $\left(\mathrm{k}_{\# 1}, \mathrm{k}_{\# 2}\right.$, and $\left.\mathrm{k}_{\# 3}[/ \mathrm{sec}]\right)$ was obtained from each experiment using Equation 1 by simple linear approximation, and the results are summarized in Table $\mathbf{S 2 5}$. The obtained values were used for following calculation of the Arrhenius and Eyring equations.

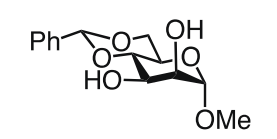

Substrate (10 mM Man 2)
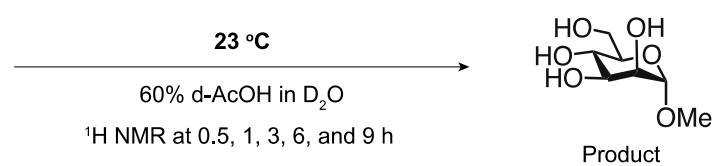

Product

Scheme S8. Hydrolysis of 4,6-O-benzylidene acetal of Man 2.

\begin{tabular}{|c|c|c|c|c|c|}
\hline & $\begin{array}{l}\text { Time point } \\
\text { [hour] }\end{array}$ & $\begin{array}{c}\int \mathbf{S} \\
\text { (Integral of substrate) }\end{array}$ & $\begin{array}{c}\int P \\
\text { (Integral of product) }\end{array}$ & $\int \mathbf{S} /\left(\int \mathbf{S}+\int \mathbf{P}\right)$ & $\ln \left[\int \mathbf{S} /\left(\int \mathbf{S}+\int \mathbf{P}\right)\right]$ \\
\hline \multirow[t]{5}{*}{ Man 2 \#1 } & 0.5 & 1 & 0.2022 & 0.8318 & -0.1842 \\
\hline & 1 & 1 & 0.4091 & 0.7097 & -0.3430 \\
\hline & 3 & 1 & 1.7565 & 0.3628 & -1.0140 \\
\hline & 6 & 1 & 6.6233 & 0.1312 & -2.0312 \\
\hline & 9 & 1 & 18.202 & 0.0521 & -2.9550 \\
\hline \multirow[t]{5}{*}{ Man 2 \#2 } & 0.5 & 1 & 0.2254 & 0.8161 & -0.2033 \\
\hline & 1 & 1 & 0.4473 & 0.6909 & -0.3697 \\
\hline & 3 & 1 & 1.655 & 0.3766 & -0.9764 \\
\hline & 6 & 1 & 5.3791 & 0.1568 & -1.8530 \\
\hline & 9 & 1 & 14.5773 & 0.0642 & -2.7458 \\
\hline
\end{tabular}




\begin{tabular}{|r|r|r|r|r|r|} 
Man 2 \#3 & 0.5 & 1 & 0.2272 & 0.8149 & -0.2047 \\
\cline { 2 - 6 } & 1 & 1 & 0.454 & 0.6878 & -0.3743 \\
\cline { 2 - 6 } & 3 & 1 & 1.7622 & 0.3620 & -1.0160 \\
\cline { 2 - 6 } & 9 & 1 & 6.3243 & 0.1365 & -1.9912 \\
\hline
\end{tabular}

Table S8. All experiments were conducted in triplicate. Man 2 \#1 stands for the $1^{\text {st }}$ experiment using Man 2 as a substrate, and ${ }^{1} \mathrm{H}$ NMR was measured at $0.5,1,3,6$, and 9 hours. Integral of substrate $\left[\int \mathrm{S}\right]$ was set as 1 , and accordingly the integral of product $\left[\int \mathrm{P}\right]$ was obtained.

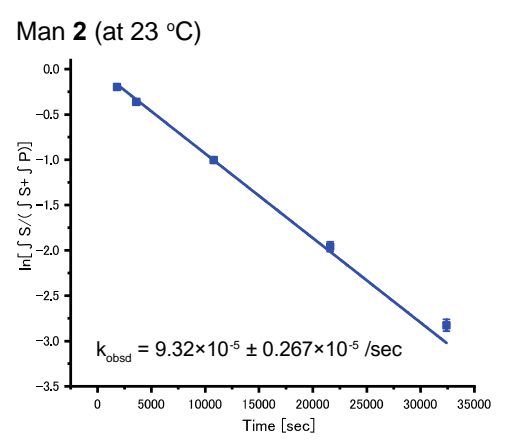

Figure S8. The values of $\ln \left[\int \mathrm{S} /\left(\int \mathrm{S}+\int \mathrm{P}\right)\right]$ obtained by three experiments were plotted as a function of time ( $\mathrm{sec}$ ), and the intercept was set at 0 . The value of $\mathrm{k}_{\mathrm{obsd}}$ was obtained by statistical analysis and the error bars are shown. In addition, the individual reaction rate constant $\left(\mathrm{k}_{\# 1}, \mathrm{k}_{\# 2}\right.$, and $\left.\mathrm{k}_{\# 3}[/ \mathrm{sec}]\right)$ was obtained from each experiment using Equation 1 by simple linear approximation, and the results are summarized in Table S25. The obtained values were used for following calculation of the Arrhenius and Eyring equations.

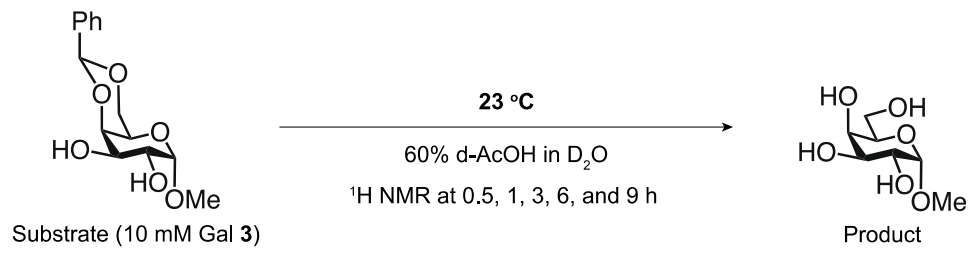

Scheme S9. Hydrolysis of 4,6-O-benzylidene acetal of Gal 3.

\begin{tabular}{|l|l|c|c|c|l|}
\hline & $\begin{array}{l}\text { Time point } \\
\text { [hour }]\end{array}$ & $\int \mathbf{S}$ & $\int \mathbf{P}$ & \\
(Integral of substrate) & (Integral of product) & $\int \mathbf{S} /\left(\int \mathbf{S}+\int \mathbf{P}\right)$ & $\ln \left[\int \mathbf{S} /\left(\int \mathbf{S}+\int \mathbf{P}\right)\right]$ \\
\hline
\end{tabular}




\begin{tabular}{|c|c|c|c|c|c|}
\hline \multirow[t]{5}{*}{ Gal 3 \#1 } & 0.5 & 1 & 0.0297 & 0.9712 & -0.0293 \\
\hline & 1 & 1 & 0.0527 & 0.9499 & -0.0514 \\
\hline & 3 & 1 & 0.1384 & 0.8784 & -0.1296 \\
\hline & 6 & 1 & 0.2608 & 0.7931 & -0.2317 \\
\hline & 9 & 1 & 0.4154 & 0.7065 & -0.3474 \\
\hline \multirow[t]{5}{*}{ Gal 3 \#2 } & 0.5 & 1 & 0.046 & 0.9560 & -0.0450 \\
\hline & 1 & 1 & 0.0565 & 0.9465 & -0.0550 \\
\hline & 3 & 1 & 0.1311 & 0.8841 & -0.1232 \\
\hline & 6 & 1 & 0.2643 & 0.7910 & -0.2345 \\
\hline & 9 & 1 & 0.407 & 0.7107 & -0.3415 \\
\hline \multirow[t]{5}{*}{ Gal 3 \#3 } & 0.5 & 1 & 0.0276 & 0.9731 & -0.0272 \\
\hline & 1 & 1 & 0.0479 & 0.9543 & -0.0468 \\
\hline & 3 & 1 & 0.1242 & 0.8895 & -0.1171 \\
\hline & 6 & 1 & 0.265 & 0.7905 & -0.2351 \\
\hline & 9 & 1 & 0.3874 & 0.7208 & -0.3274 \\
\hline
\end{tabular}

Table S9. All experiments were conducted in triplicate. Gal 3 \#1 stands for the $1^{\text {st }}$ experiment using Gal 3 as a substrate, and ${ }^{1} \mathrm{H}$ NMR was measured at $0.5,1,3,6$, and 9 hours. Integral of substrate $\left[\int \mathrm{S}\right]$ was set as 1 , and accordingly the integral of product $\left[\int \mathrm{P}\right]$ was obtained.

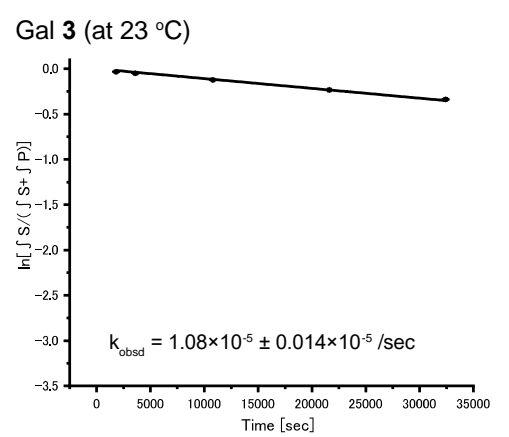

Figure S9. The values of $\ln \left[\int \mathrm{S} /\left(\int \mathrm{S}+\int \mathrm{P}\right)\right]$ obtained by three experiments were plotted as a function of time ( $\mathrm{sec}$ ), and the intercept was set at 0 . The value of $\mathrm{k}_{\mathrm{obsd}}$ was obtained by statistical analysis and the error bars are shown. In addition, the individual reaction rate constant $\left(\mathrm{k}_{\# 1}, \mathrm{k}_{\# 2}\right.$, and $\left.\mathrm{k}_{\# 3}[/ \mathrm{sec}]\right)$ was obtained from each experiment using Equation 1 by simple linear approximation, and the results are summarized in Table S25. The obtained values were used for following calculation of the Arrhenius and Eyring equations. 
1.4 Data for di-acetylated substrates $4-6$ at $23{ }^{\circ} \mathrm{C}$
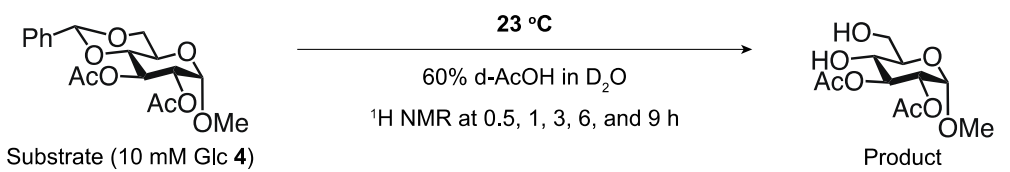

Scheme S10. Hydrolysis of 4,6-O-benzylidene acetal of Glc 4.

\begin{tabular}{|c|c|c|c|c|c|}
\hline & $\begin{array}{l}\text { Time point } \\
\text { [hour] }\end{array}$ & $\begin{array}{c}\int \mathrm{S} \\
\text { (Integral of substrate) }\end{array}$ & $\begin{array}{c}\int \mathbf{P} \\
\text { (Integral of product) }\end{array}$ & $\int \mathbf{S} /\left(\int \mathbf{S}+\int \mathbf{P}\right)$ & $\ln \left[\int \mathbf{S} /\left(\int \mathbf{S}+\int \mathbf{P}\right)\right]$ \\
\hline \multirow[t]{5}{*}{ Glc 4 \#1 } & 0.5 & 3 & 0.190 & 0.9405 & -0.0613 \\
\hline & 1 & 3 & 0.367 & 0.8909 & -0.1155 \\
\hline & 3 & 3 & 1.219 & 0.7110 & -0.3411 \\
\hline & 6 & 3 & 2.967 & 0.5028 & -0.6876 \\
\hline & 9 & 3 & 5.391 & 0.3575 & -1.0285 \\
\hline \multirow[t]{5}{*}{ Glc 4 \#2 } & 0.5 & 3 & 0.1881 & 0.9410 & -0.0608 \\
\hline & 1 & 3 & 0.3705 & 0.8901 & -0.1164 \\
\hline & 3 & 3 & 1.1699 & 0.7194 & -0.3293 \\
\hline & 6 & 3 & 2.759 & 0.5209 & -0.6522 \\
\hline & 9 & 3 & 5.0542 & 0.3725 & -0.9876 \\
\hline \multirow[t]{5}{*}{ Glc 4 \#3 } & 0.5 & 3 & 0.2896 & 0.9120 & -0.0922 \\
\hline & 1 & 3 & 0.4089 & 0.8800 & -0.1278 \\
\hline & 3 & 3 & 1.4225 & 0.6783 & -0.3881 \\
\hline & 6 & 3 & 3.3233 & 0.4744 & -0.7456 \\
\hline & 9 & 3 & 6.1926 & 0.3263 & -1.1198 \\
\hline
\end{tabular}

Table S10. All experiments were conducted in triplicate. Glc $\mathbf{4} \# 1$ stands for the $1^{\text {st }}$ experiment using Glc 4 as a substrate, and ${ }^{1} \mathrm{H}$ NMR was measured at $0.5,1,3,6$, and 9 hours. Integral of substrate $\left[\int \mathrm{S}\right]$ was set as 1 , and accordingly the integral of product $\left[\int \mathrm{P}\right]$ was obtained. 


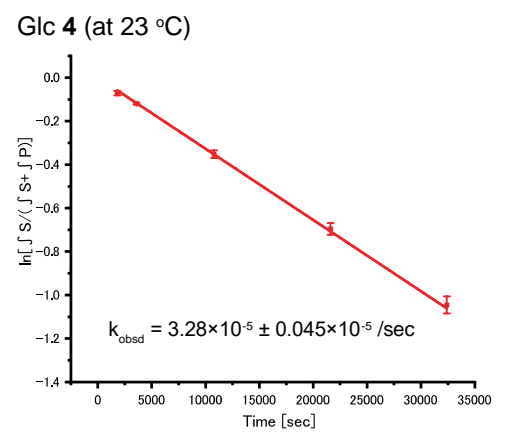

Figure S10. The values of $\ln \left[\int \mathrm{S} /\left(\int \mathrm{S}+\int \mathrm{P}\right)\right]$ obtained by three experiments were plotted as a function of time ( $\mathrm{sec}$ ), and the intercept was set at 0 . The value of $\mathrm{k}_{\mathrm{obsd}}$ was obtained by statistical analysis and the error bars are shown. In addition, the individual reaction rate constant $\left(\mathrm{k}_{\# 1}, \mathrm{k}_{\# 2}\right.$, and $\left.\mathrm{k}_{\# 3}[/ \mathrm{sec}]\right)$ was obtained from each experiment using Equation 1 by simple linear approximation, and the results are summarized in Table $\mathbf{S 2 5}$. The obtained values were used for following calculation of the Arrhenius and Eyring equations.
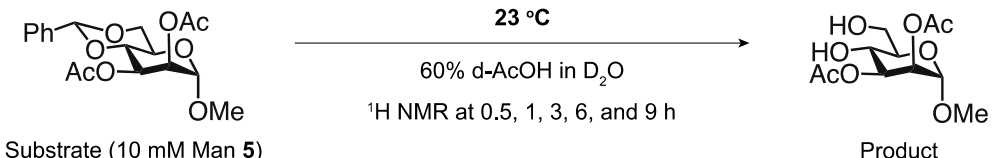

Scheme S11. Hydrolysis of 4,6-O-benzylidene acetal of Man 5.

\begin{tabular}{|c|c|c|c|c|c|}
\hline & $\begin{array}{l}\text { Time point } \\
\text { [hour] }\end{array}$ & $\begin{array}{c}\int \mathrm{S} \\
\text { (Integral of substrate) }\end{array}$ & $\begin{array}{c}\int \mathbf{P} \\
\text { (Integral of product) }\end{array}$ & $\int \mathbf{S} /\left(\int \mathbf{S}+\int \mathbf{P}\right)$ & $\ln \left[\int \mathbf{S} /\left(\int \mathbf{S}+\int \mathbf{P}\right)\right]$ \\
\hline \multirow[t]{5}{*}{ Man 5 \#1 } & 0.5 & 3 & 0.1637 & 0.9483 & -0.0531 \\
\hline & 1 & 3 & 0.3097 & 0.9064 & -0.0982 \\
\hline & 3 & 3 & 0.9052 & 0.7682 & -0.2637 \\
\hline & 6 & 3 & 2.0657 & 0.5922 & -0.5239 \\
\hline & 9 & 3 & 3.5573 & 0.4575 & -0.7820 \\
\hline \multirow[t]{4}{*}{ Man 5 \#2 } & 0.5 & 3 & 0.1684 & 0.9469 & -0.0546 \\
\hline & 1 & 3 & 0.3271 & 0.9017 & -0.1035 \\
\hline & 3 & 3 & 0.9298 & 0.7634 & -0.2700 \\
\hline & 6 & 3 & 2.0822 & 0.5903 & -0.5271 \\
\hline
\end{tabular}




\begin{tabular}{|r|r|r|r|r|r|} 
& 9 & 3 & 3.5721 & 0.4565 & -0.7842 \\
\hline Man 5 \#3 & 0.5 & 3 & 0.11811 & 0.9621 & -0.0386 \\
\cline { 2 - 6 } & 1 & 3 & 0.3483 & 0.8960 & -0.1098 \\
\cline { 2 - 6 } & 3 & 3 & 1.0287 & 0.7447 & -0.2948 \\
\cline { 2 - 6 } & 6 & 3 & 2.2787 & 0.5683 & -0.5651 \\
\cline { 2 - 6 } & 9 & 3 & 4.2724 & 0.4125 & -0.8855 \\
\hline
\end{tabular}

Table S11. All experiments were conducted in triplicate. Man 5 \#1 stands for the $1^{\text {st }}$ experiment using Man 5 as a substrate, and ${ }^{1} \mathrm{H}$ NMR was measured at $0.5,1,3,6$, and 9 hours. Integral of substrate $\left[\int \mathrm{S}\right]$ was set as 1 , and accordingly the integral of product $\left[\int \mathrm{P}\right]$ was obtained.

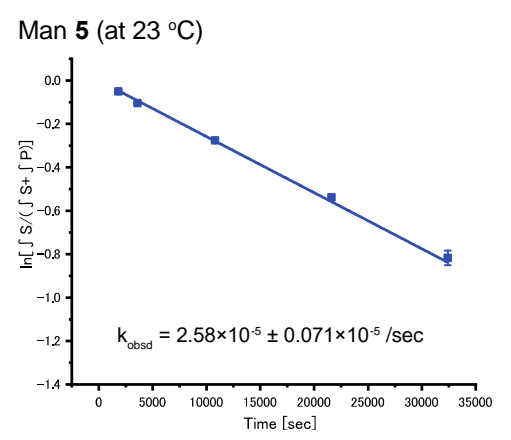

Figure S11. The values of $\ln \left[\int \mathrm{S} /\left(\int \mathrm{S}+\int \mathrm{P}\right)\right]$ obtained by three experiments were plotted as a function of time ( $\mathrm{sec}$ ), and the intercept was set at 0 . The value of $\mathrm{k}_{\mathrm{obsd}}$ was obtained by statistical analysis and the error bars are shown. In addition, the individual reaction rate constant $\left(\mathrm{k}_{\# 1}, \mathrm{k}_{\# 2}\right.$, and $\left.\mathrm{k}_{\# 3}[/ \mathrm{sec}]\right)$ was obtained from each experiment using Equation 1 by simple linear approximation, and the results are summarized in Table S25. The obtained values were used for following calculation of the Arrhenius and Eyring equations.
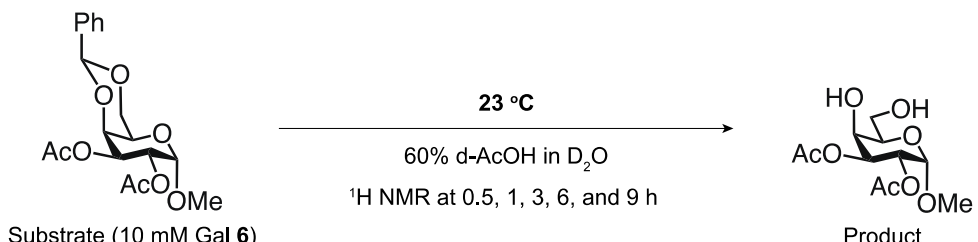

Scheme S12. Hydrolysis of 4,6-O-benzylidene acetal of Gal 6. 


\begin{tabular}{|c|c|c|c|c|c|}
\hline & $\begin{array}{l}\text { Time point } \\
\text { [hour] }\end{array}$ & $\begin{array}{c}\int \mathbf{S} \\
\text { (Integral of substrate) }\end{array}$ & $\begin{array}{c}\int \mathbf{P} \\
\text { (Integral of product) }\end{array}$ & $\int \mathbf{S} /\left(\int \mathbf{S}+\int \mathbf{P}\right)$ & $\ln \left[\int \mathbf{S} /\left(\int \mathbf{S}+\int \mathbf{P}\right)\right]$ \\
\hline \multirow[t]{5}{*}{ Gal 6 \#1 } & 0.5 & 3 & 0.0448 & 0.9853 & -0.0148 \\
\hline & 1 & 3 & 0.081 & 0.9737 & -0.0266 \\
\hline & 3 & 3 & 0.2123 & 0.9339 & -0.0684 \\
\hline & 6 & 3 & 0.4186 & 0.8776 & -0.1306 \\
\hline & 9 & 3 & 0.6283 & 0.8268 & -0.1902 \\
\hline \multirow[t]{5}{*}{ Gal 6 \#2 } & 0.5 & 3 & 0.0554 & 0.9819 & -0.0183 \\
\hline & 1 & 3 & 0.0957 & 0.9691 & -0.0314 \\
\hline & 3 & 3 & 0.2334 & 0.9278 & -0.0749 \\
\hline & 6 & 3 & 0.423 & 0.8764 & -0.1319 \\
\hline & 9 & 3 & 0.6337 & 0.8256 & -0.1916 \\
\hline \multirow[t]{5}{*}{ Gal 6 \#3 } & 0.5 & 3 & 0.051 & 0.9833 & -0.0169 \\
\hline & 1 & 3 & 0.1655 & 0.9477 & -0.0537 \\
\hline & 3 & 3 & 0.2914 & 0.9115 & -0.0927 \\
\hline & 6 & 3 & 0.4404 & 0.8720 & -0.1370 \\
\hline & 9 & 3 & 0.7146 & 0.8076 & -0.2137 \\
\hline
\end{tabular}

Table S12. All experiments were conducted in triplicate. Gal 6 \#1 stands for the $1^{\text {st }}$ experiment using Gal 6 as a substrate, and ${ }^{1} \mathrm{H}$ NMR was measured at $0.5,1,3,6$, and 9 hours. Integral of substrate $\left[\int \mathrm{S}\right]$ was set as 1 , and accordingly the integral of product $\left[\int \mathrm{P}\right]$ was obtained.

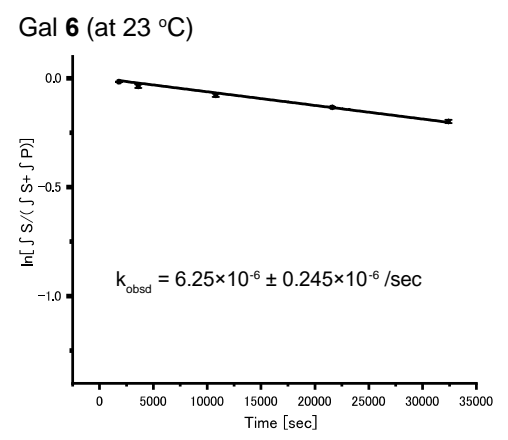

Figure S12. The values of $\ln \left[\int \mathrm{S} /\left(\int \mathrm{S}+\int \mathrm{P}\right)\right]$ obtained by three experiments were plotted as a function of time ( $\mathrm{sec}$ ), and the intercept was set at 0 . The value of $\mathrm{k}_{\mathrm{obsd}}$ was obtained by statistical analysis and the error bars are shown. In addition, the individual reaction rate constant 
$\left(\mathrm{k}_{\# 1}, \mathrm{k}_{\# 2}\right.$, and $\left.\mathrm{k}_{\# 3}[/ \mathrm{sec}]\right)$ was obtained from each experiment using Equation 1 by simple linear approximation, and the results are summarized in Table S25. The obtained values were used for following calculation of the Arrhenius and Eyring equations. 
1.5 Data for non-acetylated substrates $\mathbf{1 - 3}$ at $28{ }^{\circ} \mathrm{C}$
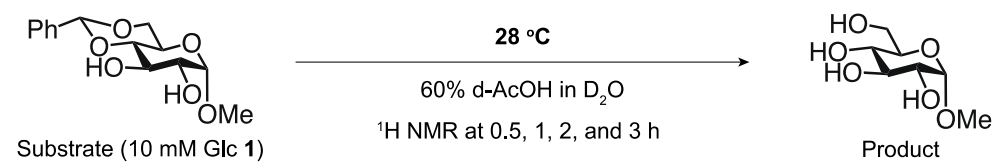

Scheme S13. Hydrolysis of 4,6-O-benzylidene acetal of Glc 1.

\begin{tabular}{|c|c|c|c|c|c|}
\hline & $\begin{array}{l}\text { Time point } \\
\text { [hour] }\end{array}$ & $\begin{array}{c}\int \mathrm{S} \\
\text { (Integral of substrate) }\end{array}$ & $\begin{array}{c}\int \mathbf{P} \\
\text { (Integral of product) }\end{array}$ & $\int \mathbf{S} /\left(\int \mathbf{S}+\int \mathbf{P}\right)$ & $\ln \left[\int \mathbf{S} /\left(\int \mathbf{S}+\int \mathbf{P}\right)\right]$ \\
\hline \multirow[t]{4}{*}{ Glc 1 \#1 } & 0.5 & 1 & 0.2641 & 0.7911 & -0.2344 \\
\hline & 1 & 1 & 0.5805 & 0.6327 & -0.4577 \\
\hline & 2 & 1 & 1.4397 & 0.4099 & -0.8919 \\
\hline & 3 & 1 & 2.7655 & 0.2656 & -1.3259 \\
\hline \multirow[t]{4}{*}{ Glc 1 \#2 } & 0.5 & 1 & 0.2681 & 0.7886 & -0.2375 \\
\hline & 1 & 1 & 0.6343 & 0.6119 & -0.4912 \\
\hline & 2 & 1 & 1.6696 & 0.3746 & -0.9819 \\
\hline & 3 & 1 & 3.3816 & 0.2282 & -1.4774 \\
\hline \multirow[t]{4}{*}{ Glc 1 \#3 } & 0.5 & 1 & 0.2945 & 0.7725 & -0.2581 \\
\hline & 1 & 1 & 0.6514 & 0.6055 & -0.5016 \\
\hline & 2 & 1 & 1.6238 & 0.3811 & -0.9646 \\
\hline & 3 & 1 & 3.389 & 0.2278 & -1.4791 \\
\hline
\end{tabular}

Table S13. All experiments were conducted in triplicate. Glc 1 \#1 stands for the $1^{\text {st }}$ experiment using Glc 1 as a substrate, and ${ }^{1} \mathrm{H}$ NMR was measured at $0.5,1,2$, and 3 hours. Integral of substrate $\left[\int \mathrm{S}\right]$ was set as 1 , and accordingly the integral of product $\left[\int \mathrm{P}\right]$ was obtained.

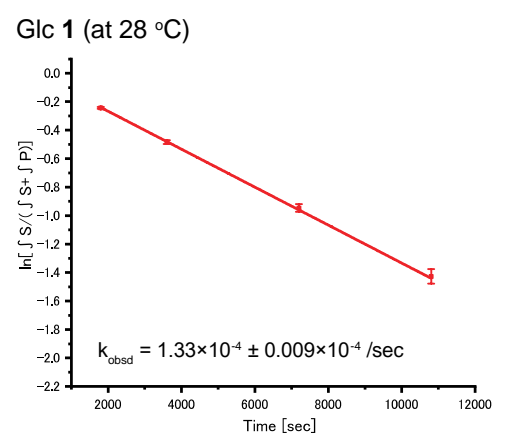


Figure S13. The values of $\ln \left[\int \mathrm{S} /\left(\int \mathrm{S}+\int \mathrm{P}\right)\right]$ obtained by three experiments were plotted as a function of time ( $\mathrm{sec})$, and the intercept was set at 0 . The value of $\mathrm{k}_{\mathrm{obsd}}$ was obtained by statistical analysis and the error bars are shown. In addition, the individual reaction rate constant $\left(\mathrm{k}_{\# 1}, \mathrm{k}_{\# 2}\right.$, and $\left.\mathrm{k}_{\# 3}[/ \mathrm{sec}]\right)$ was obtained from each experiment using Equation 1 by simple linear approximation, and the results are summarized in Table S25. The obtained values were used for following calculation of the Arrhenius and Eyring equations.
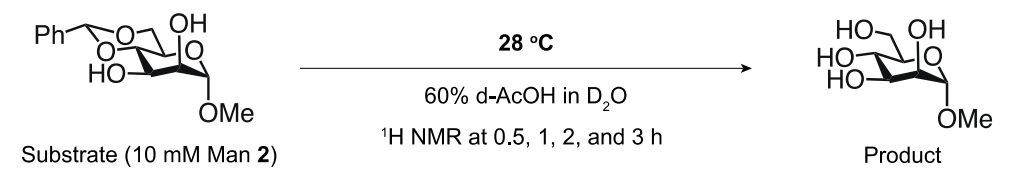

Scheme S14. Hydrolysis of 4,6-O-benzylidene acetal of Man 2.

\begin{tabular}{|c|c|c|c|c|c|}
\hline & $\begin{array}{l}\text { Time point } \\
\text { [hour] }\end{array}$ & $\begin{array}{c}\int \mathbf{S} \\
\text { (Integral of substrate) }\end{array}$ & $\begin{array}{c}\int P \\
\text { (Integral of product) }\end{array}$ & $\int \mathbf{S} /\left(\int \mathbf{S}+\int \mathbf{P}\right)$ & $\ln \left[\int \mathbf{S} /\left(\int \mathbf{S}+\int \mathbf{P}\right)\right]$ \\
\hline \multirow[t]{4}{*}{ Man 2 \#1 } & 0.5 & 1 & 0.4384 & 0.6952 & -0.3635 \\
\hline & 1 & 1 & 0.9451 & 0.5141 & -0.6653 \\
\hline & 2 & 1 & 2.6375 & 0.2749 & -1.2913 \\
\hline & 3 & 1 & 5.6881 & 0.1495 & -1.9003 \\
\hline \multirow[t]{4}{*}{ Man 2 \#2 } & 0.5 & 1 & 0.466 & 0.6821 & -0.3825 \\
\hline & 1 & 1 & 1.0629 & 0.4848 & -0.7241 \\
\hline & 2 & 1 & 3.1727 & 0.2397 & -1.4286 \\
\hline & 3 & 1 & 7.1219 & 0.1231 & -2.0946 \\
\hline \multirow[t]{4}{*}{ Man 2 \#3 } & 0.5 & 1 & 0.4154 & 0.7065 & -0.3474 \\
\hline & 1 & 1 & 0.9788 & 0.5054 & -0.6825 \\
\hline & 2 & 1 & 2.7465 & 0.2669 & -1.3208 \\
\hline & 3 & 1 & 5.6993 & 0.1493 & -1.9020 \\
\hline
\end{tabular}

Table S14. All experiments were conducted in triplicate. Man 2 \#1 stands for the $1^{\text {st }}$ experiment using Man 2 as a substrate, and ${ }^{1} \mathrm{H}$ NMR was measured at $0.5,1,2$, and 3 hours. Integral of substrate $\left[\int \mathrm{S}\right]$ was set as 1 , and accordingly the integral of product $\left[\int \mathrm{P}\right]$ was obtained. 


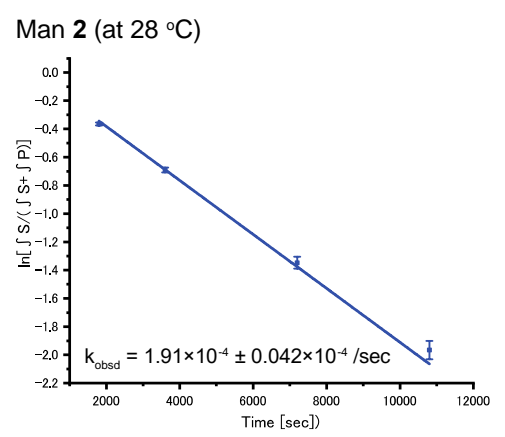

Figure S14. The values of $\ln \left[\int \mathrm{S} /\left(\int \mathrm{S}+\int \mathrm{P}\right)\right]$ obtained by three experiments were plotted as a function of time ( $\mathrm{sec}$ ), and the intercept was set at 0 . The value of $\mathrm{k}_{\mathrm{obsd}}$ was obtained by statistical analysis and the error bars are shown. In addition, the individual reaction rate constant $\left(\mathrm{k}_{\# 1}, \mathrm{k}_{\# 2}\right.$, and $\left.\mathrm{k}_{\# 3}[/ \mathrm{sec}]\right)$ was obtained from each experiment using Equation 1 by simple linear approximation, and the results are summarized in Table $\mathbf{S 2 5}$. The obtained values were used for following calculation of the Arrhenius and Eyring equations.

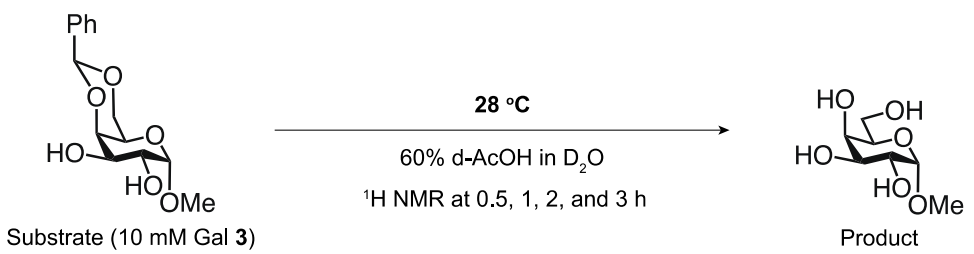

Scheme S15. Hydrolysis of 4,6-O-benzylidene acetal of Gal 3.

\begin{tabular}{|c|c|c|c|c|c|}
\hline & $\begin{array}{l}\text { Time point } \\
\text { [hour] }\end{array}$ & $\begin{array}{c}\int \mathbf{S} \\
\text { (Integral of substrate) }\end{array}$ & $\begin{array}{c}\int \mathbf{P} \\
\text { (Integral of product) }\end{array}$ & $\int \mathbf{S} /\left(\int \mathbf{S}+\int \mathbf{P}\right)$ & $\ln \left[\int \mathbf{S} /\left(\int \mathbf{S}+\int \mathbf{P}\right)\right]$ \\
\hline \multirow[t]{4}{*}{ Gal 3 \#1 } & 0.5 & 1 & 0.0389 & 0.9626 & -0.0382 \\
\hline & 1 & 1 & 0.0759 & 0.9295 & -0.0732 \\
\hline & 2 & 1 & 0.1573 & 0.8641 & -0.1461 \\
\hline & 3 & 1 & 0.2526 & 0.7983 & -0.2252 \\
\hline \multirow[t]{4}{*}{ Gal 3 \#2 } & 0.5 & 1 & 0.0545 & 0.9483 & -0.0531 \\
\hline & 1 & 1 & 0.1111 & 0.9000 & -0.1054 \\
\hline & 2 & 1 & 0.1698 & 0.8548 & -0.1568 \\
\hline & 3 & 1 & 0.2600 & 0.7937 & -0.2311 \\
\hline Gal 3 \#3 & 0.5 & 1 & 0.0555 & 0.9474 & -0.0540 \\
\hline
\end{tabular}




\begin{tabular}{|l|l|l|l|l|l|}
1 & 1 & 0.0840 & 0.9225 & -0.0807 \\
\hline 2 & 1 & 0.1721 & 0.8532 & -0.1588 \\
\hline 3 & 1 & 0.2531 & 0.7980 & -0.2256 \\
\hline
\end{tabular}

Table S15. All experiments were conducted in triplicate. Gal 3 \#1 stands for the $1^{\text {st }}$ experiment using Gal 3 as a substrate, and ${ }^{1} \mathrm{H}$ NMR was measured at $0.5,1,2$, and 3 hours. Integral of substrate $\left[\int \mathrm{S}\right]$ was set as 1 , and accordingly the integral of product $\left[\int \mathrm{P}\right]$ was obtained.

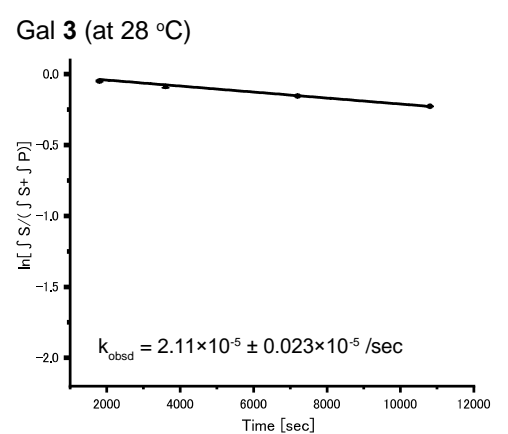

Figure S15. The values of $\ln \left[\int \mathrm{S} /\left(\int \mathrm{S}+\int \mathrm{P}\right)\right]$ obtained by three experiments were plotted as a function of time ( $\mathrm{sec}$ ), and the intercept was set at 0 . The value of $\mathrm{k}_{\text {obsd }}$ was obtained by statistical analysis and the error bars are shown. In addition, the individual reaction rate constant $\left(\mathrm{k}_{\# 1}, \mathrm{k}_{\# 2}\right.$, and $\left.\mathrm{k}_{\# 3}[/ \mathrm{sec}]\right)$ was obtained from each experiment using Equation 1 by simple linear approximation, and the results are summarized in Table $\mathbf{S 2 5}$. The obtained values were used for following calculation of the Arrhenius and Eyring equations. 
1.6 Data for di-acetylated substrates $4-6$ at $28{ }^{\circ} \mathrm{C}$
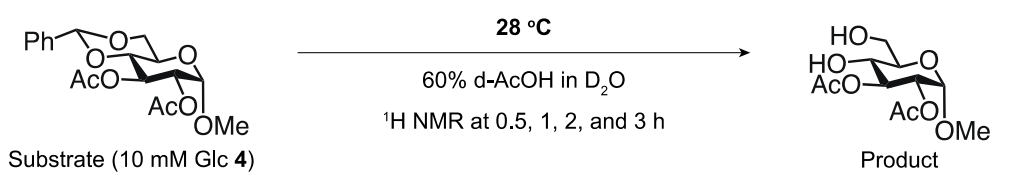

Scheme S16. Hydrolysis of 4,6-O-benzylidene acetal of Glc 4.

\begin{tabular}{|c|c|c|c|c|c|}
\hline & $\begin{array}{l}\text { Time point } \\
\text { [hour] }\end{array}$ & $\begin{array}{c}\int \mathbf{S} \\
\text { (Integral of substrate) }\end{array}$ & $\begin{array}{c}\int \mathrm{P} \\
\text { (Integral of product) }\end{array}$ & $\int \mathbf{S} /\left(\int \mathbf{S}+\int \mathbf{P}\right)$ & $\ln \left[\int \mathbf{S} /\left(\int \mathbf{S}+\int \mathbf{P}\right)\right]$ \\
\hline \multirow[t]{4}{*}{ Glc 4 \#1 } & 0.5 & 3 & 0.3438 & 0.8972 & -0.1085 \\
\hline & 1 & 3 & 0.6573 & 0.8203 & -0.1981 \\
\hline & 2 & 3 & 1.3872 & 0.6838 & -0.3801 \\
\hline & 3 & 3 & 2.2908 & 0.5670 & -0.5674 \\
\hline \multirow[t]{4}{*}{ Glc 4 \#2 } & 0.5 & 3 & 0.3456 & 0.8967 & -0.1090 \\
\hline & 1 & 3 & 0.7242 & 0.8055 & -0.2162 \\
\hline & 2 & 3 & 1.4905 & 0.6681 & -0.4034 \\
\hline & 3 & 3 & 2.4602 & 0.5494 & -0.5989 \\
\hline \multirow[t]{4}{*}{ Glc 4 \#3 } & 0.5 & 3 & 0.3462 & 0.8965 & -0.1092 \\
\hline & 1 & 3 & 0.6936 & 0.8122 & -0.2080 \\
\hline & 2 & 3 & 1.578 & 0.6553 & -0.4226 \\
\hline & 3 & 3 & 2.6082 & 0.5349 & -0.6256 \\
\hline
\end{tabular}

Table S16. All experiments were conducted in triplicate. Glc $\mathbf{4} \# 1$ stands for the $1^{\text {st }}$ experiment using Glc 4 as a substrate, and ${ }^{1} \mathrm{H}$ NMR was measured at $0.5,1,2$, and 3 hours. Integral of substrate $\left[\int \mathrm{S}\right]$ was set as 1 , and accordingly the integral of product $\left[\int \mathrm{P}\right]$ was obtained. 


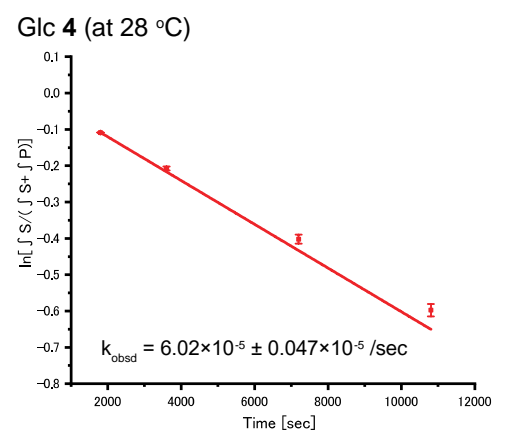

Figure S16. The values of $\ln \left[\int \mathrm{S} /\left(\int \mathrm{S}+\int \mathrm{P}\right)\right]$ obtained by three experiments were plotted as a function of time ( $\mathrm{sec}$ ), and the intercept was set at 0 . The value of $\mathrm{k}_{\mathrm{obsd}}$ was obtained by statistical analysis and the error bars are shown. In addition, the individual reaction rate constant $\left(\mathrm{k}_{\# 1}, \mathrm{k}_{\# 2}\right.$, and $\left.\mathrm{k}_{\# 3}[/ \mathrm{sec}]\right)$ was obtained from each experiment using Equation 1 by simple linear approximation, and the results are summarized in Table $\mathbf{S 2 5}$. The obtained values were used for following calculation of the Arrhenius and Eyring equations.
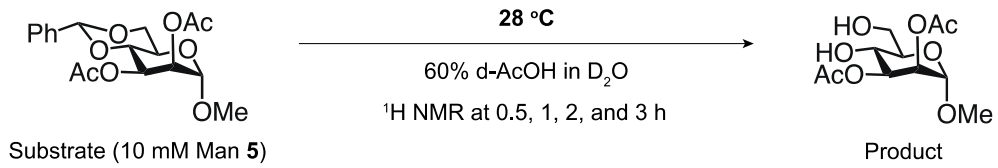

Scheme S17. Hydrolysis of 4,6-O-benzylidene acetal of Man 5.

\begin{tabular}{|c|c|c|c|c|c|}
\hline & $\begin{array}{l}\text { Time point } \\
\text { [hour] }\end{array}$ & $\begin{array}{c}\int \mathrm{S} \\
\text { (Integral of substrate) }\end{array}$ & $\begin{array}{c}\int \mathbf{P} \\
\text { (Integral of product) }\end{array}$ & $\int \mathbf{S} /\left(\int \mathbf{S}+\int \mathbf{P}\right)$ & $\ln \left[\int \mathbf{S} /\left(\int \mathbf{S}+\int \mathbf{P}\right)\right]$ \\
\hline \multirow[t]{4}{*}{ Man 5 \#1 } & 0.5 & 3 & 0.2663 & 0.9185 & -0.0850 \\
\hline & 1 & 3 & 0.5185 & 0.8526 & -0.1594 \\
\hline & 2 & 3 & 1.0307 & 0.7443 & -0.2953 \\
\hline & 3 & 3 & 1.6599 & 0.6438 & -0.4404 \\
\hline \multirow[t]{4}{*}{ Man 5 \#2 } & 0.5 & 3 & 0.2488 & 0.9234 & -0.0797 \\
\hline & 1 & 3 & 0.5184 & 0.8527 & -0.1594 \\
\hline & 2 & 3 & 1.1333 & 0.7258 & -0.3205 \\
\hline & 3 & 3 & 1.8292 & 0.6212 & -0.4761 \\
\hline
\end{tabular}




\begin{tabular}{|r|r|r|r|r|r|} 
Man 5 \#3 & 0.5 & 3 & 0.311 & 0.9061 & -0.0986 \\
\cline { 2 - 6 } & 1 & 3 & 0.6198 & 0.8288 & -0.1878 \\
\cline { 2 - 6 } & 2 & 3 & 1.2266 & 0.7098 & -0.3428 \\
\hline & 3 & 3 & 1.9961 & 0.6005 & -0.5100 \\
\hline
\end{tabular}

Table S17. All experiments were conducted in triplicate. Man $5 \# 1$ stands for the $1^{\text {st }}$ experiment using Man 5 as a substrate, and ${ }^{1} \mathrm{H}$ NMR was measured at $0.5,1,2$, and 3 hours. Integral of substrate $\left[\int \mathrm{S}\right]$ was set as 1 , and accordingly the integral of product $\left[\int \mathrm{P}\right]$ was obtained.

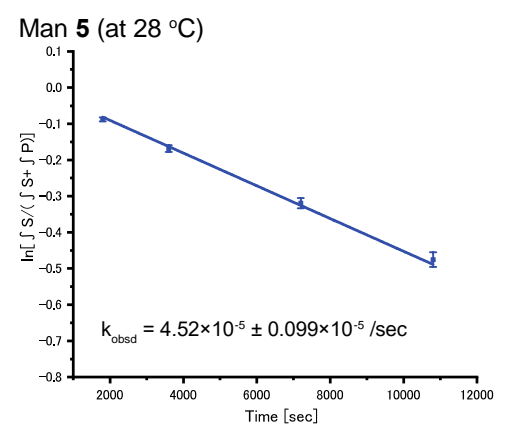

Figure S17. The values of $\ln \left[\int \mathrm{S} /\left(\int \mathrm{S}+\int \mathrm{P}\right)\right]$ obtained by three experiments were plotted as a function of time (sec), and the intercept was set at 0 . The value of $\mathrm{k}_{\text {obsd }}$ was obtained by statistical analysis and the error bars are shown. In addition, the individual reaction rate constant $\left(\mathrm{k}_{\# 1}, \mathrm{k}_{\# 2}\right.$, and $\left.\mathrm{k}_{\# 3}[/ \mathrm{sec}]\right)$ was obtained from each experiment using Equation 1 by simple linear approximation, and the results are summarized in Table $\mathbf{S 2 5}$. The obtained values were used for following calculation of the Arrhenius and Eyring equations.
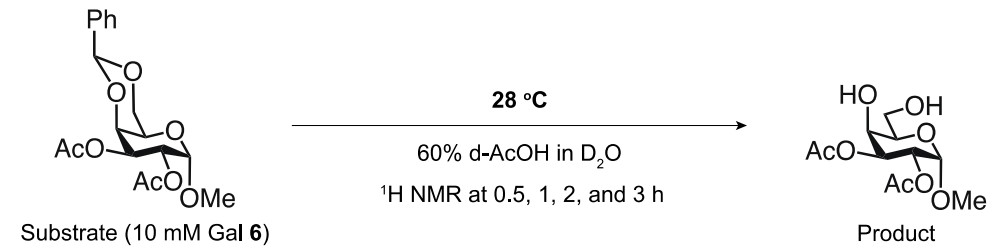

Scheme S18. Hydrolysis of 4,6-O-benzylidene acetal of Gal 6.

\begin{tabular}{|c|c|c|c|c|c|}
\hline & $\begin{array}{l}\text { Time point } \\
\text { [hour] }\end{array}$ & $\begin{array}{c}\int \mathbf{S} \\
\text { (Integral of substrate) }\end{array}$ & $\begin{array}{c}\int \mathrm{P} \\
\text { (Integral of product) }\end{array}$ & $\int \mathbf{S} /\left(\int \mathbf{S}+\int \mathbf{P}\right)$ & $\ln \left[\int \mathbf{S} /\left(\int \mathbf{S}+\int \mathbf{P}\right)\right]$ \\
\hline Gal 6 \#1 & 0.5 & 3 & 0.074 & 0.9759 & -0.0244 \\
\hline
\end{tabular}




\begin{tabular}{|r|r|r|r|r|r|} 
& 1 & 3 & 0.13 & 0.9585 & -0.0424 \\
\cline { 2 - 6 } & 2 & 3 & 0.233 & 0.9279 & -0.0748 \\
\hline \multirow{6}{*}{ Gal 6 \#2 } & 3 & 3 & 0.3496 & 0.8956 & -0.1102 \\
\cline { 2 - 6 } & 0.5 & 3 & 0.0664 & 0.9783 & -0.0219 \\
\cline { 2 - 6 } & 1 & 3 & 0.1399 & 0.9554 & -0.0456 \\
\cline { 2 - 6 } & 2 & 3 & 0.2685 & 0.9179 & -0.0857 \\
\hline \multirow{3}{*}{ Gal 6 \#3 } & 3 & 3 & 0.4022 & 0.8818 & -0.1258 \\
\cline { 2 - 6 } & 2 & 3 & 0.0782 & 0.9746 & -0.0257 \\
\cline { 2 - 6 } & 3 & 3 & 0.1386 & 0.9558 & -0.0452 \\
\cline { 2 - 6 } & 3 & 3 & 0.2485 & 0.9235 & -0.0796 \\
\cline { 2 - 6 } & 3 & 0.3717 & 0.8898 & -0.1168 \\
\hline
\end{tabular}

Table S18. All experiments were conducted in triplicate. Gal 6 \#1 stands for the $1^{\text {st }}$ experiment using Gal 6 as a substrate, and ${ }^{1} \mathrm{H}$ NMR was measured at $0.5,1,2$, and 3 hours. Integral of substrate $\left[\int \mathrm{S}\right]$ was set as 1 , and accordingly the integral of product $\left[\int \mathrm{P}\right]$ was obtained.

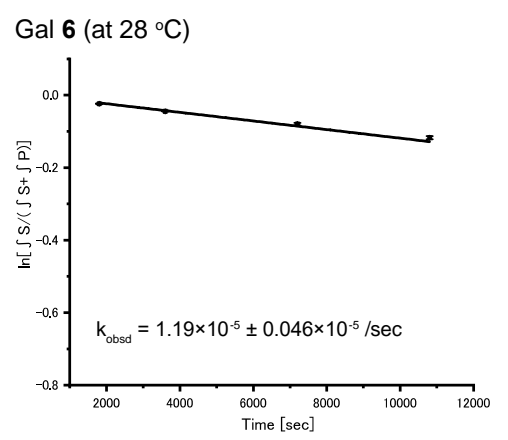

Figure S18. The values of $\ln \left[\int \mathrm{S} /\left(\int \mathrm{S}+\int \mathrm{P}\right)\right]$ obtained by three experiments were plotted as a function of time ( $\mathrm{sec}$ ), and the intercept was set at 0 . The value of $\mathrm{k}_{\mathrm{obsd}}$ was obtained by statistical analysis and the error bars are shown. In addition, the individual reaction rate constant $\left(\mathrm{k}_{\# 1}, \mathrm{k}_{\# 2}\right.$, and $\left.\mathrm{k}_{\# 3}[/ \mathrm{sec}]\right)$ was obtained from each experiment using Equation 1 by simple linear approximation, and the results are summarized in Table S25. The obtained values were used for following calculation of the Arrhenius and Eyring equations. 
1.7 Data for non-acetylated substrates $\mathbf{1 - 3}$ at $33{ }^{\circ} \mathrm{C}$
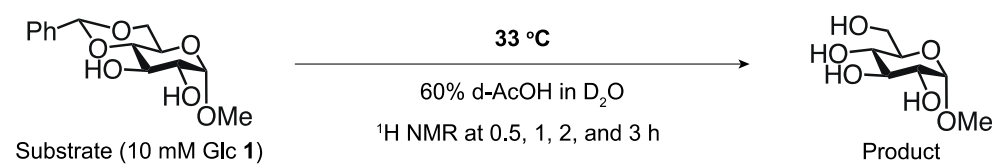

Scheme S19. Hydrolysis of 4,6-O-benzylidene acetal of Glc 1.

\begin{tabular}{|c|c|c|c|c|c|}
\hline & $\begin{array}{l}\text { Time point } \\
\text { [hour] }\end{array}$ & $\begin{array}{c}\int \mathrm{S} \\
\text { (Integral of substrate) }\end{array}$ & $\begin{array}{c}\int P \\
\text { (Integral of product) }\end{array}$ & $\int \mathbf{S} /\left(\int \mathbf{S}+\int \mathbf{P}\right)$ & $\ln \left[\int \mathbf{S} /\left(\int \mathbf{S}+\int \mathbf{P}\right)\right]$ \\
\hline \multirow[t]{4}{*}{ Glc 1 \#1 } & 0.5 & 1 & 0.4807 & 0.6754 & -0.3925 \\
\hline & 1 & 1 & 1.1412 & 0.4670 & -0.7614 \\
\hline & 2 & 1 & 3.5701 & 0.2188 & -1.5195 \\
\hline & 3 & 1 & 8.8203 & 0.1018 & -2.2845 \\
\hline \multirow[t]{4}{*}{ Glc 1 \#2 } & 0.5 & 1 & 0.4062 & 0.7111 & -0.3409 \\
\hline & 1 & 1 & 1.0058 & 0.4986 & -0.6960 \\
\hline & 2 & 1 & 3.0326 & 0.2480 & -1.3944 \\
\hline & 3 & 1 & 7.3927 & 0.1192 & -2.1274 \\
\hline \multirow[t]{4}{*}{ Glc $1 \# 3$} & 0.5 & 1 & 0.4651 & 0.6825 & -0.3819 \\
\hline & 1 & 1 & 1.0538 & 0.4869 & -0.7197 \\
\hline & 2 & 1 & 3.6513 & 0.2150 & -1.5371 \\
\hline & 3 & 1 & 7.2425 & 0.1213 & -2.1093 \\
\hline
\end{tabular}

Table S19. All experiments were conducted in triplicate. Glc 1 \#1 stands for the $1^{\text {st }}$ experiment using Glc 1 as a substrate, and ${ }^{1} \mathrm{H}$ NMR was measured at $0.5,1,2$, and 3 hours. Integral of substrate $\left[\int \mathrm{S}\right]$ was set as 1 , and accordingly the integral of product $\left[\int \mathrm{P}\right]$ was obtained.

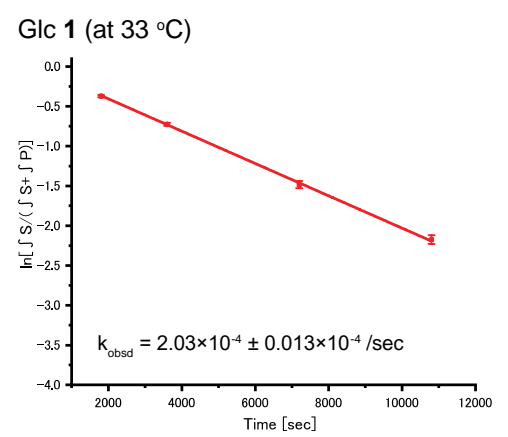


Figure S19. The values of $\ln \left[\int \mathrm{S} /\left(\int \mathrm{S}+\int \mathrm{P}\right)\right]$ obtained by three experiments were plotted as a function of time (sec), and the intercept was set at 0 . The value of $k_{\text {obsd }}$ was obtained by statistical analysis and the error bars are shown. In addition, the individual reaction rate constant $\left(\mathrm{k}_{\# 1}, \mathrm{k}_{\# 2}\right.$, and $\left.\mathrm{k}_{\# 3}[/ \mathrm{sec}]\right)$ was obtained from each experiment using Equation 1 by simple linear approximation, and the results are summarized in Table S25. The obtained values were used for following calculation of the Arrhenius and Eyring equations.
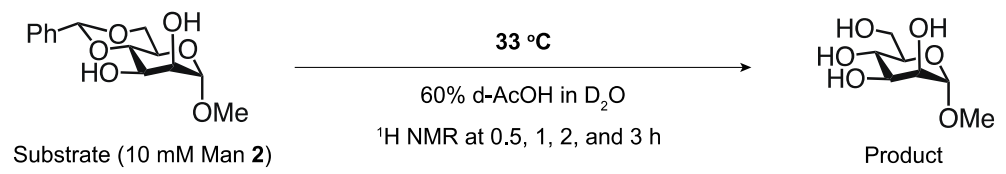

Scheme S20. Hydrolysis of 4,6-O-benzylidene acetal of Man 2.

\begin{tabular}{|c|c|c|c|c|c|}
\hline & $\begin{array}{l}\text { Time point } \\
\text { [hour] }\end{array}$ & $\begin{array}{c}\int \mathbf{S} \\
\text { (Integral of substrate) }\end{array}$ & $\begin{array}{c}\int \mathbf{P} \\
\text { (Integral of product) }\end{array}$ & $\int \mathbf{S} /\left(\int \mathbf{S}+\int \mathbf{P}\right)$ & $\ln \left[\int \mathbf{S} /\left(\int \mathbf{S}+\int \mathbf{P}\right)\right]$ \\
\hline \multirow[t]{4}{*}{ Man 2 \#1 } & 0.5 & 1 & 0.6338 & 0.6121 & -0.4909 \\
\hline & 1 & 1 & 1.8283 & 0.3536 & -1.0397 \\
\hline & 2 & 1 & 7.2396 & 0.1214 & -2.1090 \\
\hline & 3 & 1 & 22.5472 & 0.0425 & -3.1590 \\
\hline \multirow[t]{4}{*}{ Man 2 \#2 } & 0.5 & 1 & 0.5705 & 0.6367 & -0.4514 \\
\hline & 1 & 1 & 1.4716 & 0.4046 & -0.9049 \\
\hline & 2 & 1 & 5.8708 & 0.1455 & -1.9273 \\
\hline & 3 & 1 & 16.4243 & 0.0574 & -2.8579 \\
\hline \multirow[t]{4}{*}{ Man 2 \#3 } & 0.5 & 1 & 0.7983 & 0.5561 & -0.5868 \\
\hline & 1 & 1 & 2.0951 & 0.3231 & -1.1298 \\
\hline & 2 & 1 & 7.7004 & 0.1149 & -2.1634 \\
\hline & 3 & 1 & 21.2437 & 0.0450 & -3.1021 \\
\hline
\end{tabular}

Table S20. All experiments were conducted in triplicate. Man 2 \#1 stands for the $1^{\text {st }}$ experiment using Man 2 as a substrate, and ${ }^{1} \mathrm{H}$ NMR was measured at $0.5,1,2$, and 3 hours. Integral of substrate $\left[\int \mathrm{S}\right]$ was set as 1 , and accordingly the integral of product $\left[\int \mathrm{P}\right]$ was obtained. 


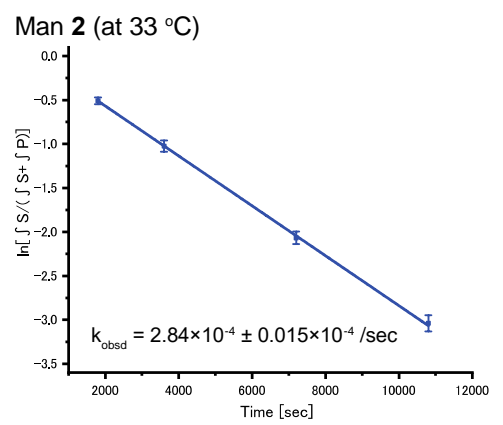

Figure S20. The values of $\ln \left[\int \mathrm{S} /\left(\int \mathrm{S}+\int \mathrm{P}\right)\right]$ obtained by three experiments were plotted as a function of time ( $\mathrm{sec}$ ), and the intercept was set at 0 . The value of $\mathrm{k}_{\text {obsd }}$ was obtained by statistical analysis and the error bars are shown. In addition, the individual reaction rate constant $\left(\mathrm{k}_{\# 1}, \mathrm{k}_{\# 2}\right.$, and $\left.\mathrm{k}_{\# 3}[/ \mathrm{sec}]\right)$ was obtained from each experiment using Equation 1 by simple linear approximation, and the results are summarized in Table $\mathbf{S 2 5}$. The obtained values were used for following calculation of the Arrhenius and Eyring equations.

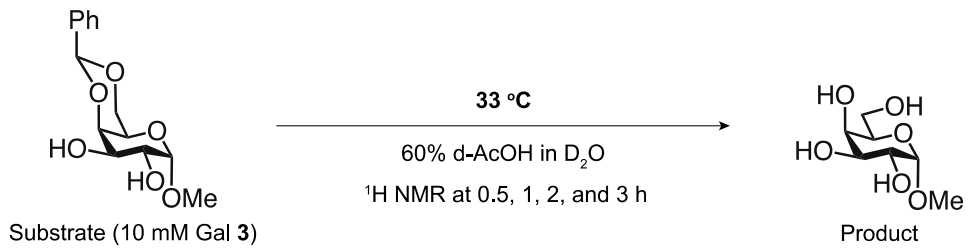

Scheme S21. Hydrolysis of 4,6-O-benzylidene acetal of Gal 3.

\begin{tabular}{|c|c|c|c|c|c|}
\hline & $\begin{array}{l}\text { Time point } \\
\text { [hour] }\end{array}$ & $\begin{array}{c}\int \mathrm{S} \\
\text { (Integral of substrate) }\end{array}$ & $\begin{array}{c}\int \mathbf{P} \\
\text { (Integral of product) }\end{array}$ & $\int \mathbf{S} /\left(\int \mathbf{S}+\int \mathbf{P}\right)$ & $\ln \left[\int \mathbf{S} /\left(\int \mathbf{S}+\int \mathbf{P}\right)\right]$ \\
\hline \multirow[t]{4}{*}{ Gal 3 \#1 } & 0.5 & 1 & 0.0705 & 0.9341 & -0.0681 \\
\hline & 1 & 1 & 0.1376 & 0.8790 & -0.1289 \\
\hline & 2 & 1 & 0.3016 & 0.7683 & -0.2636 \\
\hline & 3 & 1 & 0.5014 & 0.6660 & -0.4064 \\
\hline \multirow[t]{4}{*}{ Gal 3 \#2 } & 0.5 & 1 & 0.0712 & 0.9335 & -0.0688 \\
\hline & 1 & 1 & 0.1397 & 0.8774 & -0.1308 \\
\hline & 2 & 1 & 0.2805 & 0.7809 & -0.2473 \\
\hline & 3 & 1 & 0.4384 & 0.6952 & -0.3635 \\
\hline Gal 3 \#3 & 0.5 & 1 & 0.0768 & 0.9287 & -0.0740 \\
\hline
\end{tabular}




\begin{tabular}{|r|r|r|r|r|r|} 
& 1 & 1 & 0.1891 & 0.8410 & -0.1732 \\
\hline 2 & 1 & 0.3219 & 0.7565 & -0.2791 \\
\hline 3 & 1 & 0.4925 & 0.6700 & -0.4005 \\
\hline
\end{tabular}

Table S21. All experiments were conducted in triplicate. Gal 3 \#1 stands for the $1^{\text {st }}$ experiment using Gal 3 as a substrate, and ${ }^{1} \mathrm{H}$ NMR was measured at $0.5,1,2$, and 3 hours. Integral of substrate $\left[\int \mathrm{S}\right]$ was set as 1 , and accordingly the integral of product $\left[\int \mathrm{P}\right]$ was obtained.

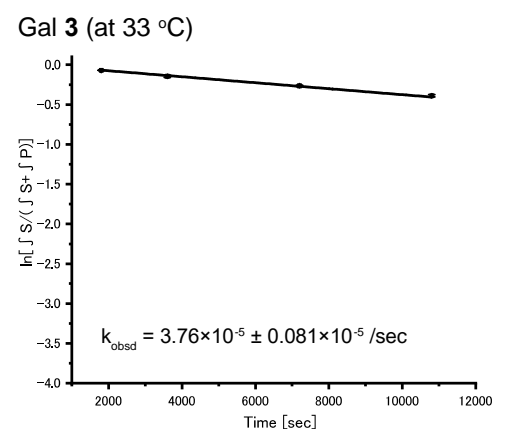

Figure S21. The values of $\ln \left[\int \mathrm{S} /\left(\int \mathrm{S}+\int \mathrm{P}\right)\right]$ obtained by three experiments were plotted as a function of time ( $\mathrm{sec}$ ), and the intercept was set at 0 . The value of $\mathrm{k}_{\text {obsd }}$ was obtained by statistical analysis and the error bars are shown. In addition, the individual reaction rate constant $\left(\mathrm{k}_{\# 1}, \mathrm{k}_{\# 2}\right.$, and $\left.\mathrm{k}_{\# 3}[/ \mathrm{sec}]\right)$ was obtained from each experiment using Equation 1 by simple linear approximation, and the results are summarized in Table $\mathbf{S 2 5}$. The obtained values were used for following calculation of the Arrhenius and Eyring equations. 
1.8 Data for di-acetylated substrates $4-6$ at $33{ }^{\circ} \mathrm{C}$
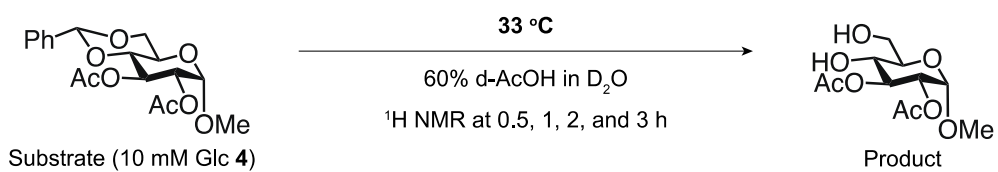

Scheme S22. Hydrolysis of 4,6-O-benzylidene acetal of Glc 4.

\begin{tabular}{|c|c|c|c|c|c|}
\hline & $\begin{array}{l}\text { Time point } \\
\text { [hour] }\end{array}$ & $\begin{array}{c}\int \mathrm{S} \\
\text { (Integral of substrate) }\end{array}$ & $\begin{array}{c}\int \mathbf{P} \\
\text { (Integral of product) }\end{array}$ & $\int \mathbf{S} /\left(\int \mathbf{S}+\int \mathbf{P}\right)$ & $\ln \left[\int \mathbf{S} /\left(\int \mathbf{S}+\int \mathbf{P}\right)\right]$ \\
\hline \multirow[t]{4}{*}{ Glc 4 \#1 } & 0.5 & 3 & 0.6175 & 0.8293 & -0.1872 \\
\hline & 1 & 3 & 1.2453 & 0.7067 & -0.3472 \\
\hline & 2 & 3 & 3.0841 & 0.4931 & -0.7071 \\
\hline & 3 & 3 & 5.7801 & 0.3417 & -1.0739 \\
\hline \multirow[t]{4}{*}{ Glc 4 \#2 } & 0.5 & 3 & 0.4258 & 0.8757 & -0.1327 \\
\hline & 1 & 3 & 0.9976 & 0.7505 & -0.2871 \\
\hline & 2 & 3 & 2.4307 & 0.5524 & -0.5935 \\
\hline & 3 & 3 & 4.7821 & 0.3855 & -0.9532 \\
\hline \multirow[t]{4}{*}{ Glc 4 \#3 } & 0.5 & 3 & 0.6337 & 0.8256 & -0.1916 \\
\hline & 1 & 3 & 1.2778 & 0.7013 & -0.3548 \\
\hline & 2 & 3 & 3.1527 & 0.4876 & -0.7183 \\
\hline & 3 & 3 & 5.4516 & 0.3550 & -1.0357 \\
\hline
\end{tabular}

Table S22. All experiments were conducted in triplicate. Glc $\mathbf{4} \# 1$ stands for the $1^{\text {st }}$ experiment using Glc 4 as a substrate, and ${ }^{1} \mathrm{H}$ NMR was measured at $0.5,1,2$, and 3 hours. Integral of substrate $\left[\int \mathrm{S}\right]$ was set as 1 , and accordingly the integral of product $\left[\int \mathrm{P}\right]$ was obtained.

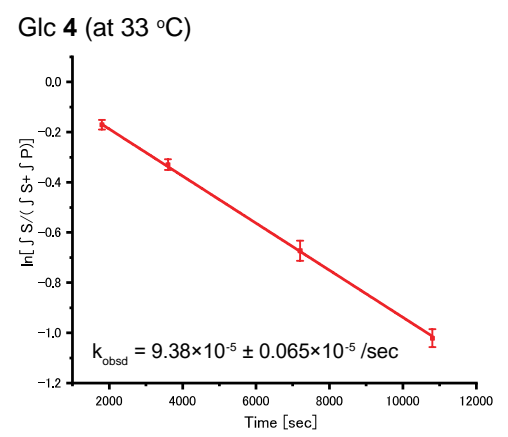


Figure S22. The values of $\ln \left[\int \mathrm{S} /\left(\int \mathrm{S}+\int \mathrm{P}\right)\right]$ obtained by three experiments were plotted as a function of time (sec), and the intercept was set at 0 . The value of $k_{\text {obsd }}$ was obtained by statistical analysis and the error bars are shown. In addition, the individual reaction rate constant $\left(\mathrm{k}_{\# 1}, \mathrm{k}_{\# 2}\right.$, and $\left.\mathrm{k}_{\# 3}[/ \mathrm{sec}]\right)$ was obtained from each experiment using Equation 1 by simple linear approximation, and the results are summarized in Table S25. The obtained values were used for following calculation of the Arrhenius and Eyring equations.
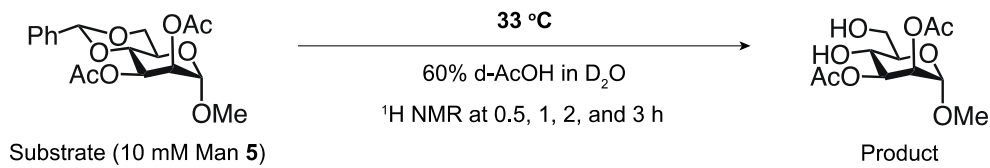

Scheme S23. Hydrolysis of 4,6-O-benzylidene acetal of Man $\mathbf{5}$.

\begin{tabular}{|c|c|c|c|c|c|}
\hline & $\begin{array}{l}\text { Time point } \\
\text { [hour] }\end{array}$ & $\begin{array}{c}\int \mathrm{S} \\
\text { (Integral of substrate) }\end{array}$ & $\begin{array}{c}\int \mathbf{P} \\
\text { (Integral of product) }\end{array}$ & $\int \mathbf{S} /\left(\int \mathbf{S}+\int \mathbf{P}\right)$ & $\ln \left[\int \mathbf{S} /\left(\int \mathbf{S}+\int \mathbf{P}\right)\right]$ \\
\hline \multirow[t]{4}{*}{ Man 4 \#1 } & 0.5 & 3 & 0.3996 & 0.8825 & -0.1250 \\
\hline & 1 & 3 & 0.8611 & 0.7770 & -0.2523 \\
\hline & 2 & 3 & 2.0347 & 0.5959 & -0.5177 \\
\hline & 3 & 3 & 3.6129 & 0.4537 & -0.7904 \\
\hline \multirow[t]{4}{*}{ Man 4 \#2 } & 0.5 & 3 & 0.3531 & 0.8947 & -0.1113 \\
\hline & 1 & 3 & 0.7619 & 0.7975 & -0.2263 \\
\hline & 2 & 3 & 1.8738 & 0.6155 & -0.4853 \\
\hline & 3 & 3 & 3.3987 & 0.4688 & -0.7575 \\
\hline \multirow[t]{4}{*}{ Man 4 \#3 } & 0.5 & 3 & 0.5103 & 0.8546 & -0.1571 \\
\hline & 1 & 3 & 1.0615 & 0.7386 & -0.3029 \\
\hline & 2 & 3 & 2.3273 & 0.5631 & -0.5742 \\
\hline & 3 & 3 & 4.1552 & 0.4193 & -0.8692 \\
\hline
\end{tabular}

Table S23. All experiments were conducted in triplicate. Man $5 \# 1$ stands for the $1^{\text {st }}$ experiment using Man 5 as a substrate, and ${ }^{1} \mathrm{H}$ NMR was measured at $0.5,1,2$, and 3 hours. Integral of substrate $\left[\int \mathrm{S}\right]$ was set as 1 , and accordingly the integral of product $\left[\int \mathrm{P}\right]$ was obtained. 


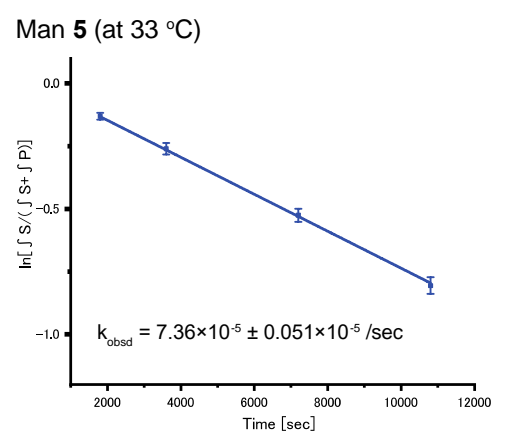

Figure S23. The values of $\ln \left[\int \mathrm{S} /\left(\int \mathrm{S}+\int \mathrm{P}\right)\right]$ obtained by three experiments were plotted as a function of time (sec), and the intercept was set at 0 . The value of $k_{\text {obsd }}$ was obtained by statistical analysis and the error bars are shown. In addition, the individual reaction rate constant $\left(\mathrm{k}_{\# 1}, \mathrm{k}_{\# 2}\right.$, and $\left.\mathrm{k}_{\# 3}[/ \mathrm{sec}]\right)$ was obtained from each experiment using Equation 1 by simple linear approximation, and the results are summarized in Table $\mathbf{S 2 5}$. The obtained values were used for following calculation of the Arrhenius and Eyring equations.
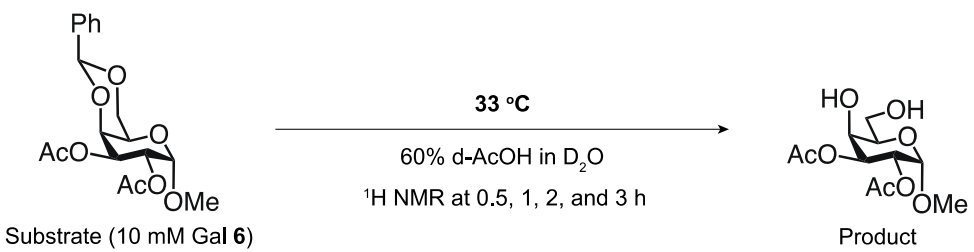

Scheme S24. Hydrolysis of 4,6-O-benzylidene acetal of Gal 6.

\begin{tabular}{|c|c|c|c|c|c|}
\hline & $\begin{array}{l}\text { Time point } \\
\text { [hour] }\end{array}$ & $\begin{array}{c}\int \mathrm{S} \\
\text { (Integral of substrate) }\end{array}$ & $\begin{array}{c}\int \mathbf{P} \\
\text { (Integral of product) }\end{array}$ & $\int \mathbf{S} /\left(\int \mathbf{S}+\int \mathbf{P}\right)$ & $\ln \left[\int \mathbf{S} /\left(\int \mathbf{S}+\int \mathbf{P}\right)\right]$ \\
\hline \multirow[t]{4}{*}{ Gal 6 \#1 } & 0.5 & 3 & 0.1154 & 0.9630 & -0.0377 \\
\hline & 1 & 3 & 0.2056 & 0.9359 & -0.0663 \\
\hline & 2 & 3 & 0.4129 & 0.8790 & -0.1290 \\
\hline & 3 & 3 & 0.6806 & 0.8151 & -0.2045 \\
\hline \multirow[t]{4}{*}{ Gal 6 \#2 } & 0.5 & 3 & 0.0988 & 0.9681 & -0.0324 \\
\hline & 1 & 3 & 0.1951 & 0.9389 & -0.0630 \\
\hline & 2 & 3 & 0.4232 & 0.8764 & -0.1320 \\
\hline & 3 & 3 & 0.5981 & 0.8338 & -0.1818 \\
\hline
\end{tabular}




\begin{tabular}{|r|r|r|r|r|r|} 
Gal 6 \#3 & 0.5 & 3 & 0.1485 & 0.9528 & -0.0483 \\
\cline { 2 - 6 } & 1 & 3 & 0.2493 & 0.9233 & -0.0798 \\
\cline { 2 - 6 } & 2 & 3 & 0.4678 & 0.8651 & -0.1449 \\
\hline
\end{tabular}

Table S24. All experiments were conducted in triplicate. Gal $\mathbf{6} \# 1$ stands for the $1^{\text {st }}$ experiment using Gal 6 as a substrate, and ${ }^{1} \mathrm{H}$ NMR was measured at $0.5,1,2$, and 3 hours. Integral of substrate $\left[\int \mathrm{S}\right]$ was set as 1 , and accordingly the integral of product $\left[\int \mathrm{P}\right]$ was obtained.

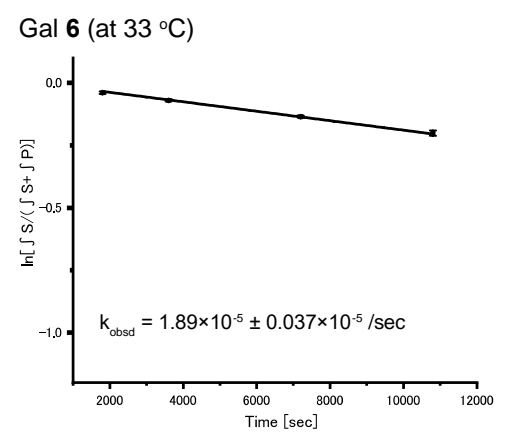

Figure S24. The values of $\ln \left[\int \mathrm{S} /\left(\int \mathrm{S}+\int \mathrm{P}\right)\right]$ obtained by three experiments were plotted as a function of time (sec), and the intercept was set at 0 . The value of $\mathrm{k}_{\text {obsd }}$ was obtained by statistical analysis and the error bars are shown. In addition, the individual reaction rate constant $\left(\mathrm{k}_{\# 1}, \mathrm{k}_{\# 2}\right.$, and $\left.\mathrm{k}_{\# 3}[/ \mathrm{sec}]\right)$ was obtained from each experiment using Equation 1 by simple linear approximation, and the results are summarized in Table S25. The obtained values were used for following calculation of the Arrhenius and Eyring equations. 


\subsection{List of reaction constant $(\mathrm{k}), \ln (\mathrm{k})$, and $\ln (\mathrm{k} / \mathrm{T})$}

\begin{tabular}{|c|c|c|c|c|c|c|c|}
\hline & & Glc 1 & Glc 4 & Man 2 & Man 5 & Gal 3 & Gal 6 \\
\hline \multirow[t]{3}{*}{$10{ }^{\circ} \mathrm{C} \# 1^{[1]}$} & $k_{\# 1}$ & 0.00001560 & 0.00000782 & 0.00002472 & 0.00000634 & 0.00000315 & 0.00000168 \\
\hline & $\ln \left(k_{\sharp 1}\right)$ & -11.068 & -11.759 & -10.608 & -11.969 & -12.668 & -13.297 \\
\hline & $\ln \left(k_{\# 1} / T\right)$ & -16.714 & -17.404 & -16.253 & -17.614 & -18.314 & -18.942 \\
\hline \multirow[t]{3}{*}{$10^{\circ} \mathrm{C} \mathrm{\# 2}$} & $\mathrm{k}_{\# 2}$ & 0.00001524 & 0.00000855 & 0.00002216 & 0.00000684 & 0.00000326 & 0.00000262 \\
\hline & $\ln \left(k_{\# 2}\right)$ & -11.092 & -11.670 & -10.717 & -11.893 & -12.634 & -12.852 \\
\hline & $\ln \left(\mathrm{k}_{\# 2} / \mathrm{T}\right)$ & -16.737 & -17.315 & -16.363 & -17.538 & -18.279 & -18.498 \\
\hline \multirow[t]{3}{*}{$10^{\circ} \mathrm{C} \mathrm{\# 3}$} & $k_{\# 3}$ & 0.00001548 & 0.00000780 & 0.00002281 & 0.00000650 & 0.00000309 & 0.00000164 \\
\hline & $\ln \left(k_{\# 3}\right)$ & -11.076 & -11.761 & -10.688 & -11.944 & -12.687 & -13.321 \\
\hline & $\ln \left(k_{\# 3} / T\right)$ & -16.721 & -17.407 & -16.334 & -17.589 & -18.333 & -18.966 \\
\hline \multirow[t]{3}{*}{$23^{\circ} \mathrm{C} \# 1$} & $k_{\# 1}$ & 0.00005736 & 0.00003176 & 0.00009225 & 0.00002422 & 0.00001085 & 0.00000597 \\
\hline & $\ln \left(k_{\# 1}\right)$ & -9.7662 & -10.357 & -9.2910 & -10.628 & -11.431 & -12.029 \\
\hline & $\ln \left(k_{\# 1} / T\right)$ & -15.457 & -16.048 & -14.981 & -16.319 & -17.122 & -17.719 \\
\hline \multirow[t]{3}{*}{$23^{\circ} \mathrm{C} \mathrm{\# 2}$} & $\mathrm{k}_{\# 2}$ & 0.00005955 & 0.00003042 & 0.00008564 & 0.00002436 & 0.00001076 & 0.00000607 \\
\hline & $\ln \left(k_{\# 2}\right)$ & -9.7287 & -10.400 & -9.3654 & -10.623 & -11.440 & -12.012 \\
\hline & $\ln \left(\mathrm{k}_{\# 2} / \mathrm{T}\right)$ & -15.419 & -16.091 & -15.056 & -16.313 & -17.130 & -17.703 \\
\hline \multirow[t]{3}{*}{$23^{\circ} \mathrm{C} \mathrm{\# 3}$} & $k_{\# 3}$ & 0.00005898 & 0.00003469 & 0.00008830 & 0.00002701 & 0.00001041 & 0.00000673 \\
\hline & $\ln \left(k_{\# 3}\right)$ & -9.7383 & -10.269 & -9.3348 & -10.519 & -11.473 & -11.909 \\
\hline & $\ln \left(k_{\# 3} / T\right)$ & -15.429 & -15.959 & -15.025 & -16.210 & -17.163 & -17.599 \\
\hline \multirow[t]{3}{*}{$28^{\circ} \mathrm{C} \# 1$} & $k_{\# 1}$ & 0.00012351 & 0.00005292 & 0.00017799 & 0.00004120 & 0.00002066 & 0.00001043 \\
\hline & $\ln \left(k_{\# 1}\right)$ & -8.9992 & -9.8467 & -8.6338 & -10.097 & -10.787 & -11.471 \\
\hline & $\ln \left(k_{\# 1} / T\right)$ & -14.706 & -15.554 & -14.341 & -15.804 & -16.494 & -17.178 \\
\hline \multirow[t]{3}{*}{$28^{\circ} \mathrm{C} \# 2$} & $k_{\# 2}$ & 0.00013657 & 0.00005602 & 0.00019603 & 0.00004422 & 0.00002220 & 0.00001180 \\
\hline & $\ln \left(k_{\# 2}\right)$ & -8.8987 & -9.7898 & -8.5372 & -10.026 & -10.715 & -11.347 \\
\hline & $\ln \left(\mathrm{k}_{\# 2} / \mathrm{T}\right)$ & -14.606 & -15.497 & -14.244 & -15.733 & -16.423 & -17.055 \\
\hline \multirow[t]{3}{*}{$28^{\circ} \mathrm{C} \# 3$} & $k_{\# 3}$ & 0.00013640 & 0.00005818 & 0.00017941 & 0.00004781 & 0.00002148 & 0.00001106 \\
\hline & $\ln \left(k_{\# 3}\right)$ & -8.8999 & -9.7520 & -8.6258 & -9.9483 & -10.748 & -11.412 \\
\hline & $\ln \left(\mathrm{k}_{\# 3} / \mathrm{T}\right)$ & -14.607 & -15.459 & -14.333 & -15.655 & -16.455 & -17.119 \\
\hline \multirow[t]{2}{*}{$33^{\circ} \mathrm{C} \# 1$} & $k_{\# 1}$ & 0.00021150 & 0.00009896 & 0.00029201 & 0.00007255 & 0.00003722 & 0.00001864 \\
\hline & $\ln \left(k_{\# 1}\right)$ & -8.4613 & -9.2208 & -8.1387 & -9.5312 & -10.199 & -10.890 \\
\hline
\end{tabular}




\begin{tabular}{|l|l|r|r|r|r|r|r|} 
& $\ln \left(k_{\# 1} / T\right)$ & -14.185 & -14.944 & -13.862 & -15.255 & -15.922 & -16.614 \\
\hline $33{ }^{\circ} \mathrm{C} \# 2$ & $k_{\# 2}$ & 0.00019566 & 0.00008577 & 0.00026430 & 0.00006871 & 0.00003412 & 0.00001732 \\
\hline & $\ln \left(k_{\# 2}\right)$ & -8.5391 & -9.3638 & -8.2384 & -9.5856 & -10.286 & -10.964 \\
\hline & $\ln \left(k_{\# 2} / T\right)$ & -14.263 & -15.087 & -13.962 & -15.309 & -16.009 & -16.687 \\
\hline $33^{\circ} \mathrm{C} \# 3$ & $k_{\# 3}$ & 0.00020103 & 0.00009736 & 0.00029349 & 0.00008066 & 0.00003840 & 0.00002039 \\
\hline & $\ln \left(k_{\# 3}\right)$ & -8.5121 & -9.2371 & -8.1337 & -9.4253 & -10.167 & -10.800 \\
\hline & $\ln \left(k_{\sharp 3} / T\right)$ & -14.236 & -14.961 & -13.857 & -15.149 & -15.891 & -16.524 \\
\hline
\end{tabular}

Table S25. The values of $k$ were obtained from the plotting described above. The $k, \ln (k)$, and $\ln (\mathrm{k} / \mathrm{T})$ values were summarized for monosaccharide substrates. [1] “ $10^{\circ} \mathrm{C} \# 1$ " stands for the $1^{\text {st }}$ experiment performed at $10{ }^{\circ} \mathrm{C}$. Experiments were repeated three times at each reaction temperature as mentioned above. 
1.10 Arrhenius plot

Glc 1

\begin{tabular}{|r|r|r|r|r|r|}
\hline & \multicolumn{1}{|l|}{$\ln \left(\mathrm{k}_{\# 1}\right)$} & \multicolumn{1}{l|}{$\ln \left(\mathrm{k}_{\# 2}\right)$} & \multicolumn{1}{l|}{$\ln \left(\mathrm{k}_{\# 3}\right)$} & \multicolumn{1}{l|}{ Average } & Standard Error \\
\hline 3.534 & -11.068 & -11.092 & -11.076 & -11.079 & 0.012 \\
\hline 3.497 & -9.7662 & -9.7287 & -9.7383 & -9.744 & 0.019 \\
\hline 3.322 & -8.9992 & -8.8987 & -8.8999 & -8.933 & 0.058 \\
\hline 3.268 & -8.4613 & -8.5391 & -8.5121 & -8.504 & 0.040 \\
\hline
\end{tabular}

Table S26. These values are used for the Arrhenius plot according to Equation $\mathbf{3}$ as shown in Figure 2a. Then, values of the intercept $(21.45 \pm 1.85)$ and the slope $(-9.21 \pm 0.54)$ were obtained. The obtained values were furthermore used for the calculation of $\mathrm{E}_{\mathrm{a}}(\mathrm{kJ} / \mathrm{mol})$ and $A$ (/sec) as shown in Figure 2e.

Man 2

$1 / T(\times 1000)$

\begin{tabular}{|r|r|r|r|r|r|}
\hline & \multicolumn{1}{|l|}{$\ln \left(\mathrm{k}_{\# 1}\right)$} & \multicolumn{1}{l|}{$\ln \left(\mathrm{k}_{\# 2}\right)$} & \multicolumn{1}{l|}{$\ln \left(\mathrm{k}_{\# 3}\right)$} & \multicolumn{1}{l|}{ Average } & Standard Error \\
\hline 3.534 & -10.608 & -10.717 & -10.688 & -10.671 & 0.056 \\
\hline 3.497 & -9.2910 & -9.3654 & -9.3348 & -9.330 & 0.037 \\
\hline 3.322 & -8.6338 & -8.5372 & -8.6258 & -8.599 & 0.054 \\
\hline 3.268 & -8.1387 & -8.2384 & -8.1337 & -8.170 & 0.059 \\
\hline
\end{tabular}

Table S27. These values are used for the Arrhenius plot according to Equation $\mathbf{3}$ as shown in Figure 2a. Then, values of the intercept $(22.96 \pm 2.26)$ and the slope $(-9.53 \pm 0.67)$ were obtained. The obtained values were furthermore used for the calculation of $\mathrm{E}_{\mathrm{a}}(\mathrm{kJ} / \mathrm{mol})$ and $A$ (/sec) as shown in Figure 2e.

Gal 3

\begin{tabular}{|c|c|c|c|c|c|c|}
\hline & & $\ln \left(k_{\# 1}\right)$ & $\ln \left(\mathrm{k}_{\# 2}\right)$ & $\ln \left(k_{\# 3}\right)$ & Average & Standard Error \\
\hline \multirow{4}{*}{$1 / \mathrm{T}(\times 1000)$} & 3.534 & -12.668 & -12.634 & -12.687 & -12.663 & 0.027 \\
\hline & 3.497 & -11.431 & -11.440 & -11.473 & -11.448 & 0.022 \\
\hline & 3.322 & -10.787 & -10.715 & -10.748 & -10.750 & 0.036 \\
\hline & 3.268 & -10.199 & -10.286 & -10.167 & -10.217 & 0.062 \\
\hline
\end{tabular}

Table S28. These values are used for the Arrhenius plot according to Equation 3 as shown in Figure 2a. Then, values of the intercept $(18.06 \pm 2.60)$ and the slope $(-8.71 \pm 0.76)$ were 
obtained. The obtained values were furthermore used for the calculation of $\mathrm{E}_{\mathrm{a}}(\mathrm{kJ} / \mathrm{mol})$ and $A$ $(/ \mathrm{sec})$ as shown in Figure 2e.

Glc 4

\begin{tabular}{|c|c|c|c|c|c|c|}
\hline \multirow{5}{*}{$1 / \mathrm{T}(\times 1000)$} & & $\ln \left(\mathrm{k}_{\# 1}\right)$ & $\ln \left(\mathrm{k}_{\# 2}\right)$ & $\ln \left(\mathrm{k}_{\# 3}\right)$ & Average & Standard Error \\
\hline & 3.534 & -11.759 & -11.670 & -11.761 & -11.730 & 0.052 \\
\hline & 3.497 & -10.357 & -10.400 & -10.269 & -10.342 & 0.067 \\
\hline & 3.322 & -9.8467 & -9.7898 & -9.7520 & -9.796 & 0.048 \\
\hline & 3.268 & -9.2208 & -9.3638 & -9.2371 & -9.274 & 0.078 \\
\hline
\end{tabular}

Table S29. These values are used for the Arrhenius plot according to Equation 3 as shown in Figure 2b. Then, values of the intercept $(20.64 \pm 0.43)$ and the slope $(-9.16 \pm 0.13)$ were obtained. The obtained values were furthermore used for the calculation of $\mathrm{E}_{\mathrm{a}}(\mathrm{kJ} / \mathrm{mol})$ and $A$ (/sec) as shown in Figure 2e.

Man 5

\begin{tabular}{|r|r|r|r|r|r|}
\hline & \multicolumn{1}{|l|}{$\ln \left(\mathrm{K}_{\# 1}\right)$} & $\ln \left(\mathrm{k}_{\# 2}\right)$ & \multicolumn{1}{l|}{$\ln \left(\mathrm{K}_{\# 3}\right)$} & \multicolumn{1}{l|}{ Average } & Standard Error \\
\hline 3.534 & -11.969 & -11.893 & -11.944 & -11.935 & 0.039 \\
\hline 3.497 & -10.628 & -10.623 & -10.519 & -10.590 & 0.062 \\
\hline 3.322 & -10.097 & -10.026 & -9.9483 & -10.024 & 0.074 \\
\hline 3.268 & -9.5312 & -9.5856 & -9.4253 & -9.514 & 0.082 \\
\hline
\end{tabular}

Table S30. These values are used for the Arrhenius plot according to Equation $\mathbf{3}$ as shown in Figure 2b. Then, values of the intercept $(19.82 \pm 0.63)$ and the slope $(-8.99 \pm 0.18)$ were obtained. The obtained values were furthermore used for the calculation of $\mathrm{E}_{\mathrm{a}}(\mathrm{kJ} / \mathrm{mol})$ and $A$ (/sec) as shown in Figure 2e.

Gal 6

\begin{tabular}{|r|r|r|r|r|r|}
\hline & \multicolumn{1}{|l|}{$\ln \left(\mathrm{k}_{\# 1}\right)$} & \multicolumn{1}{l|}{$\ln \left(\mathrm{k}_{\# 2}\right)$} & \multicolumn{1}{l|}{$\ln \left(\mathrm{k}_{\# 3}\right)$} & \multicolumn{1}{l|}{ Average } & Standard Error \\
\hline 3.534 & -13.297 & -12.852 & -13.321 & -13.157 & 0.264 \\
\hline 3.497 & -12.029 & -12.012 & -11.909 & -11.983 & 0.065 \\
\hline 3.322 & -11.471 & -11.347 & -11.412 & -11.410 & 0.062 \\
\hline 3.268 & -10.890 & -10.964 & -10.800 & -10.885 & 0.082 \\
\hline
\end{tabular}


Table S31. These values are used for the Arrhenius plot according to Equation 3 as shown in Figure $2 \mathbf{b}$. Then, values of the intercept $(19.72 \pm 2.13)$ and the slope $(-9.37 \pm 0.64)$ were obtained. The obtained values were furthermore used for the calculation of $\mathrm{E}_{\mathrm{a}}(\mathrm{kJ} / \mathrm{mol})$ and $A$ (/sec) as shown in Figure 2e. 
1.11 Eyring plot

Glc 1

\begin{tabular}{|r|r|r|r|r|r|}
\hline & \multicolumn{1}{|l|}{$\ln \left(\mathrm{k}_{\sharp 1} / \mathrm{T}\right)$} & $\ln \left(\mathrm{k}_{\sharp 2} / \mathrm{T}\right)$ & $\ln \left(\mathrm{k}_{\sharp 3} / \mathrm{T}\right)$ & \multicolumn{1}{l|}{ Average } & \multicolumn{1}{l|}{ standard error } \\
\hline 3.534 & -16.714 & -16.737 & -16.721 & -16.724 & 0.012 \\
\hline 3.497 & -15.457 & -15.419 & -15.429 & -15.435 & 0.020 \\
\hline 3.322 & -14.706 & -14.606 & -14.607 & -14.640 & 0.057 \\
\hline 3.268 & -14.185 & -14.263 & -14.236 & -14.228 & 0.040 \\
\hline
\end{tabular}

Table S32. These values are used for the Eyring plot according to Equation 5 as shown in

Figure 2c. Then, values of the intercept $(14.77 \pm 1.83)$ and the slope $(-8.92 \pm 0.53)$ were obtained.

The obtained values were furthermore used for the calculation of $\Delta \mathrm{H}^{\ddagger}(\mathrm{kJ} / \mathrm{mol})$ and $\mathrm{T} \Delta \mathrm{S}^{\ddagger}$

$(\mathrm{kJ} / \mathrm{mol}, \mathrm{T}$ was set at $298 \mathrm{~K})$ as shown in Figure 2e.

Man 2

$T(\times 1000)$

\begin{tabular}{|r|r|r|r|r|r|}
\hline & \multicolumn{1}{|l|}{$\ln \left(\mathrm{k}_{\# 1} / \mathrm{T}\right)$} & \multicolumn{1}{|l|}{$\ln \left(\mathrm{k}_{\# 2} / \mathrm{T}\right)$} & \multicolumn{1}{l|}{$\ln \left(\mathrm{k}_{\# 3} / \mathrm{T}\right)$} & \multicolumn{1}{l|}{ Average } & \multicolumn{1}{|l|}{ standard error } \\
\hline 3.534 & -16.253 & -16.363 & -16.334 & -16.317 & 0.057 \\
\hline 3.497 & -14.981 & -15.056 & -15.025 & -15.021 & 0.038 \\
\hline 3.322 & -14.341 & -14.244 & -14.333 & -14.306 & 0.054 \\
\hline 3.268 & -13.862 & -13.962 & -13.857 & -13.894 & 0.059 \\
\hline
\end{tabular}

Table S33. These values are used for the Eyring plot according to Equation $\mathbf{5}$ as shown in

Figure 2c. Then, values of the intercept $(16.30 \pm 2.26)$ and the slope $(-9.25 \pm 0.67)$ were obtained.

The obtained values were furthermore used for the calculation of $\Delta \mathrm{H}^{\ddagger}(\mathrm{kJ} / \mathrm{mol})$ and $\mathrm{T} \Delta \mathrm{S}^{\ddagger}$

$(\mathrm{kJ} / \mathrm{mol}$, T was set at $298 \mathrm{~K})$ as shown in Figure 2e.

Gal 3

\begin{tabular}{|r|r|r|r|r|r|}
\hline & \multicolumn{1}{|l|}{$\ln \left(\mathrm{k}_{\# 1} / \mathrm{T}\right)$} & \multicolumn{1}{l|}{$\ln \left(\mathrm{k}_{\# 2} / \mathrm{T}\right)$} & \multicolumn{1}{l|}{$\ln \left(\mathrm{k}_{\# 3} / \mathrm{T}\right)$} & \multicolumn{1}{l|}{ Average } & \multicolumn{1}{|l|}{ standard error } \\
\hline 3.534 & -18.314 & -18.279 & -18.333 & -18.309 & 0.027 \\
\hline 3.497 & -17.122 & -17.130 & -17.163 & -17.138 & 0.022 \\
\hline 3.322 & -16.494 & -16.423 & -16.455 & -16.457 & 0.036 \\
\hline 3.268 & -15.922 & -16.009 & -15.891 & -15.941 & 0.061 \\
\hline
\end{tabular}

Table S34. These values are used for the Eyring plot according to Equation 5 as shown in

Figure 2c. Then, values of the intercept $(11.43 \pm 2.64)$ and the slope $(-8.43 \pm 0.77)$ were obtained.

The obtained values were furthermore used for the calculation of $\Delta \mathrm{H}^{\ddagger}(\mathrm{kJ} / \mathrm{mol})$ and $\mathrm{T} \Delta \mathrm{S}^{\ddagger}$

$(\mathrm{kJ} / \mathrm{mol}$, T was set at $298 \mathrm{~K})$ as shown in Figure $2 \mathrm{e}$. 
Glc 4

\begin{tabular}{|r|r|r|r|r|r|}
\hline & \multicolumn{1}{l|}{$\ln \left(\mathrm{k}_{\# 1} / \mathrm{T}\right)$} & $\ln \left(\mathrm{k}_{\# 2} / \mathrm{T}\right)$ & \multicolumn{1}{l|}{ Average } & standard error \\
\hline 3.534 & -17.404 & -17.315 & -17.407 & -17.375 & 0.052 \\
\hline 3.497 & -16.048 & -16.091 & -15.959 & -16.033 & 0.067 \\
\hline 3.322 & -15.554 & -15.497 & -15.459 & -15.503 & 0.048 \\
\hline 3.268 & -14.944 & -15.087 & -14.961 & -14.997 & 0.078 \\
\hline
\end{tabular}

Table S35. These values are used for the Eyring plot according to Equation $\mathbf{5}$ as shown in

Figure 2d. Then, values of the intercept $(13.97 \pm 0.43)$ and the slope $(-8.87 \pm 0.13)$ were obtained.

The obtained values were furthermore used for the calculation of $\Delta \mathrm{H}^{\ddagger}(\mathrm{kJ} / \mathrm{mol})$ and $\mathrm{T} \Delta \mathrm{S}^{\ddagger}$

$(\mathrm{kJ} / \mathrm{mol}, \mathrm{T}$ was set at $298 \mathrm{~K})$ as shown in Figure 2e.

Man 5

$/ T(\times 1000)$

\begin{tabular}{|r|r|r|r|r|r|}
\hline & \multicolumn{1}{|l|}{$\ln \left(\mathrm{k}_{\# 1} / \mathrm{T}\right)$} & \multicolumn{1}{l|}{$\ln \left(\mathrm{k}_{\# 2} / \mathrm{T}\right)$} & $\ln \left(\mathrm{k}_{\# 3} / \mathrm{T}\right)$ & \multicolumn{1}{l|}{ Average } & standard error \\
\hline 3.534 & -17.614 & -17.538 & -17.589 & -17.580 & 0.039 \\
\hline 3.497 & -16.319 & -16.313 & -16.210 & -16.281 & 0.061 \\
\hline 3.322 & -15.804 & -15.733 & -15.655 & -15.731 & 0.075 \\
\hline 3.268 & -15.255 & -15.309 & -15.149 & -15.238 & 0.081 \\
\hline
\end{tabular}

Table S36. These values are used for the Eyring plot according to Equation $\mathbf{5}$ as shown in

Figure 2d. Then, values of the intercept $(13.14 \pm 0.63)$ and the slope $(-8.69 \pm 0.18)$ were obtained.

The obtained values were furthermore used for the calculation of $\Delta \mathrm{H}^{\ddagger}(\mathrm{kJ} / \mathrm{mol})$ and $\mathrm{T} \Delta \mathrm{S}^{\ddagger}$

$(\mathrm{kJ} / \mathrm{mol}$, T was set at $298 \mathrm{~K})$ as shown in Figure 2e.

Gal 6

\begin{tabular}{|r|r|r|r|r|r|}
\hline & $\ln \left(\mathrm{k}_{\# 1} / \mathrm{T}\right)$ & \multicolumn{1}{l|}{$\ln \left(\mathrm{k}_{\# 2} / \mathrm{T}\right)$} & \multicolumn{1}{l|}{$\ln \left(\mathrm{K}_{\# 3} / \mathrm{T}\right)$} & \multicolumn{1}{l|}{ Average } & standard error \\
\hline 3.534 & -18.942 & -18.498 & -18.966 & -18.802 & 0.264 \\
\hline 3.497 & -17.719 & -17.703 & -17.599 & -17.674 & 0.065 \\
\hline 3.322 & -17.178 & -17.055 & -17.119 & -17.117 & 0.062 \\
\hline 3.268 & -16.614 & -16.687 & -16.524 & -16.608 & 0.082 \\
\hline
\end{tabular}

Table S37. These values are used for the Eyring plot according to Equation 5 as shown in

Figure 2d. Then, values of the intercept $(13.02 \pm 2.11)$ and the slope $(-9.07 \pm 0.63)$ were obtained.

The obtained values were furthermore used for the calculation of $\Delta \mathrm{H}^{\ddagger}(\mathrm{kJ} / \mathrm{mol})$ and $\mathrm{T} \Delta \mathrm{S}^{\ddagger}$

$(\mathrm{kJ} / \mathrm{mol}$, T was set at $298 \mathrm{~K})$ as shown in Figure $2 \mathbf{e}$. 
1.12 Calculation of $\Delta \mathrm{G}^{\ddagger}$ based on the Eyring equation

Glc 1

\begin{tabular}{|c|c|c|c|c|c|c|}
\hline $\mathrm{T}[\mathrm{k}]$ & $\mathrm{k}_{\# 1}$ & $\mathrm{k}_{22}$ & $\mathrm{k}_{22}$ & $\Delta \mathrm{G}^{\ddagger} \# 1$ & $\Delta \mathrm{G}^{\ddagger} \# 2$ & $\Delta \mathrm{G}^{\ddagger} \# 3$ \\
\hline 283 & 0.00001560 & 0.00001524 & 0.00001548 & 95.23 & 95.28 & 95.25 \\
\hline 296 & 0.00005683 & 0.00005825 & 0.000064 & 96.53 & 96.47 & 96.24 \\
\hline 301 & 0.00012351 & 0.00013657 & 0.0001364 & 96.26 & 96.01 & 96.01 \\
\hline 306 & 0.00020045 & 0.00019432 & 0.00020103 & 96.67 & 96.75 & 96.66 \\
\hline
\end{tabular}

Table S38. The values of $\Delta \mathrm{G}^{\ddagger}$ were obtained using the values of $\mathrm{k}$ at each reaction temperature and the Equation 6. Based on the values of $\Delta \mathrm{G}^{\star}{ }_{11}, \Delta \mathrm{G}^{\star}{ }_{22}$, and $\Delta \mathrm{G}^{\star}{ }_{33}$, we obtained $\Delta \mathrm{G}^{\star}$ of Glc $1(96.12 \pm 0.17 \mathrm{~kJ} / \mathrm{mol})$.

Man 2

\begin{tabular}{|r|c|c|c|r|r|r|}
\hline \multicolumn{1}{|l|}{$\mathrm{T}[\mathrm{k}]$} & \multicolumn{1}{|c|}{$\mathrm{k} \# 1$} & $\mathrm{k} \# 2$ & \multicolumn{1}{c|}{$\mathrm{k} \# 2$} & \multicolumn{1}{c|}{$\Delta \mathrm{G}^{\ddagger} \# 1$} & \multicolumn{1}{c|}{$\Delta \mathrm{G}^{\ddagger} \# 2$} & \multicolumn{1}{c|}{$\Delta \mathrm{G}^{\ddagger} \# 3$} \\
\hline 283 & 0.00002472 & 0.00002216 & 0.00002281 & 94.15 & 94.40 & 94.34 \\
\hline 296 & 0.00008572 & 0.00008353 & 0.00009377 & 95.52 & 95.59 & 95.30 \\
\hline 301 & 0.00017799 & 0.00019603 & 0.00017941 & 95.35 & 95.11 & 95.33 \\
\hline 306 & 0.00027265 & 0.00025877 & 0.00029349 & 95.89 & 96.02 & 95.70 \\
\hline
\end{tabular}

Table S39. The values of $\Delta \mathrm{G}^{\ddagger}$ were obtained using the values of $\mathrm{k}$ at each reaction temperature and the Equation 6. Based on the values of $\Delta \mathrm{G}^{\ddagger}$ 1, $\Delta \mathrm{G}^{\ddagger} \# 2$, and $\Delta \mathrm{G}^{\ddagger} \# 3$, we obtained $\Delta \mathrm{G}^{\ddagger}$ of Man $2(95.22 \pm 0.18 \mathrm{~kJ} / \mathrm{mol})$.

Gal 3

\begin{tabular}{|c|c|c|c|c|c|c|}
\hline $\mathrm{T}[\mathrm{k}]$ & $k_{\# 1}$ & $\mathrm{k} \# 2$ & $\mathrm{k} \# 2$ & $\Delta G^{\ddagger} \# 1$ & $\Delta \mathrm{G}^{\ddagger} \# 2$ & $\Delta G^{\ddagger} \# 3$ \\
\hline 283 & 0.00000315 & 0.00000326 & 0.00000309 & 98.99 & 98.91 & 99.04 \\
\hline 296 & 0.00001073 & 0.00001078 & 0.00001044 & 100.64 & 100.62 & 100.70 \\
\hline 301 & 0.00002066 & 0.00002220 & 0.00002148 & 100.74 & 100.56 & 100.64 \\
\hline 306 & 0.00003868 & 0.00003537 & 0.00003804 & 100.86 & 101.09 & 100.90 \\
\hline
\end{tabular}

Table S40. The values of $\Delta \mathrm{G}^{\ddagger}$ were obtained using the values of $\mathrm{k}$ at each reaction temperature and the Equation 6. Based on the values of $\Delta \mathrm{G}_{\# 1}^{\ddagger}, \Delta \mathrm{G}^{\ddagger}$, and $\Delta \mathrm{G}^{\star}{ }_{33}$, we obtained $\Delta \mathrm{G}^{\ddagger}$ of $\mathrm{Gal}$ $3(100.31 \pm 0.23 \mathrm{~kJ} / \mathrm{mol})$. 
Glc 4

\begin{tabular}{|r|c|c|c|r|r|r|}
\hline \multicolumn{1}{|l|}{$\mathrm{T}[\mathrm{k}]$} & \multicolumn{1}{|c|}{$\mathrm{K}_{\# 1}$} & \multicolumn{1}{|c|}{$\mathrm{K}_{\# 2}$} & \multicolumn{1}{c|}{$\mathrm{K}_{\# 2}$} & \multicolumn{1}{|c|}{$\Delta \mathrm{G}^{\ddagger} \# 1$} & \multicolumn{1}{|c|}{$\Delta \mathrm{G}^{\ddagger} \# 2$} & \multicolumn{1}{|c|}{$\Delta \mathrm{G}^{\ddagger} \# 3$} \\
\hline 283 & 0.00000782 & 0.00000845 & 0.00000779 & 96.85 & 96.67 & 96.86 \\
\hline 296 & 0.00003158 & 0.00003035 & 0.00003493 & 97.98 & 98.08 & 97.73 \\
\hline 301 & 0.00005292 & 0.00005818 & 0.00005818 & 98.38 & 98.15 & 98.15 \\
\hline 306 & 0.00009926 & 0.00009026 & 0.00009736 & 98.46 & 98.70 & 98.51 \\
\hline
\end{tabular}

Table S41. The values of $\Delta \mathrm{G}^{\ddagger}$ were obtained using the values of $\mathrm{k}$ at each reaction temperature and the Equation 6. Based on the values of $\Delta \mathrm{G}_{\# 1}^{\ddagger}, \Delta \mathrm{G}^{\dagger} \# 2$, and $\Delta \mathrm{G}^{\ddagger} \# 3$, we obtained $\Delta \mathrm{G}^{\ddagger}$ of Glc $4(97.88 \pm 0.20 \mathrm{~kJ} / \mathrm{mol})$.

Man 5

\begin{tabular}{|c|c|c|c|c|c|c|}
\hline $\mathrm{T}[\mathrm{k}]$ & $\mathrm{k} \# 1$ & $\mathrm{k} \# 2$ & $\mathrm{k} \# 2$ & $\Delta \mathrm{G}^{\ddagger} \# 1$ & $\Delta G^{\ddagger} \# 2$ & $\Delta \mathrm{G}^{\ddagger} \# 3$ \\
\hline 283 & 0.00000634 & 0.00000667 & 0.00000650 & 97.35 & 97.23 & 97.29 \\
\hline 296 & 0.00002421 & 0.00002418 & 0.00002712 & 98.63 & 98.64 & 98.35 \\
\hline 301 & 0.00004210 & 0.00004422 & 0.00004782 & 98.96 & 98.83 & 98.64 \\
\hline 306 & 0.00007177 & 0.00006919 & 0.00008066 & 99.29 & 99.38 & 98.99 \\
\hline
\end{tabular}

Table S42. The values of $\Delta \mathrm{G}^{\ddagger}$ were obtained using the values of $\mathrm{k}$ at each reaction temperature and the Equation 6. Based on the values of $\Delta \mathrm{G}_{\# 1}^{\ddagger}, \Delta \mathrm{G}_{\# 2}^{\ddagger}$, and $\Delta \mathrm{G}_{\# 3}^{\ddagger}$, we obtained $\Delta \mathrm{G}^{\ddagger}$ of Man $5(98.46 \pm 0.22 \mathrm{~kJ} / \mathrm{mol})$.

Gal 6

\begin{tabular}{|r|c|c|c|r|r|r|}
\hline \multicolumn{1}{|l|}{$T[\mathrm{k}]$} & \multicolumn{1}{|c|}{$\mathrm{k}_{\# 1}$} & $\mathrm{k}_{\# 2}$ & \multicolumn{1}{c|}{$\mathrm{k} \# 2_{2}$} & \multicolumn{1}{c|}{$\Delta \mathrm{G}_{\# 1}^{\ddagger}$} & \multicolumn{1}{|c|}{$\Delta \mathrm{G}^{\ddagger} \# 2$} & \multicolumn{1}{c|}{$\Delta \mathrm{G}^{\ddagger} \# 3$} \\
\hline 283 & 0.00000168 & 0.00000224 & 0.00000164 & 100.47 & 99.80 & 100.53 \\
\hline 296 & 0.00000587 & 0.00000620 & 0.00000668 & 102.12 & 101.99 & 101.80 \\
\hline 301 & 0.00001043 & 0.00001180 & 0.00001106 & 102.45 & 102.14 & 102.30 \\
\hline 306 & 0.0000183 & 0.00001865 & 0.00002138 & 102.76 & 102.71 & 102.37 \\
\hline
\end{tabular}

Table S43. The values of $\Delta \mathrm{G}^{\ddagger}$ were obtained using the values of $\mathrm{k}$ at each reaction temperature and the Equation 6. Based on the values of $\Delta \mathrm{G}^{\ddagger}{ }_{\# 1}, \Delta \mathrm{G}^{\ddagger}{ }_{2}$, and $\Delta \mathrm{G}^{\ddagger}{ }_{33}$, we obtained $\Delta \mathrm{G}^{\ddagger}$ of $\mathrm{Gal}$ $6(101.79 \pm 0.28 \mathrm{~kJ} / \mathrm{mol})$. 
$2.1{ }^{1} \mathrm{H},{ }^{13} \mathrm{C}$ NMR spectra of compound $\mathbf{1}$

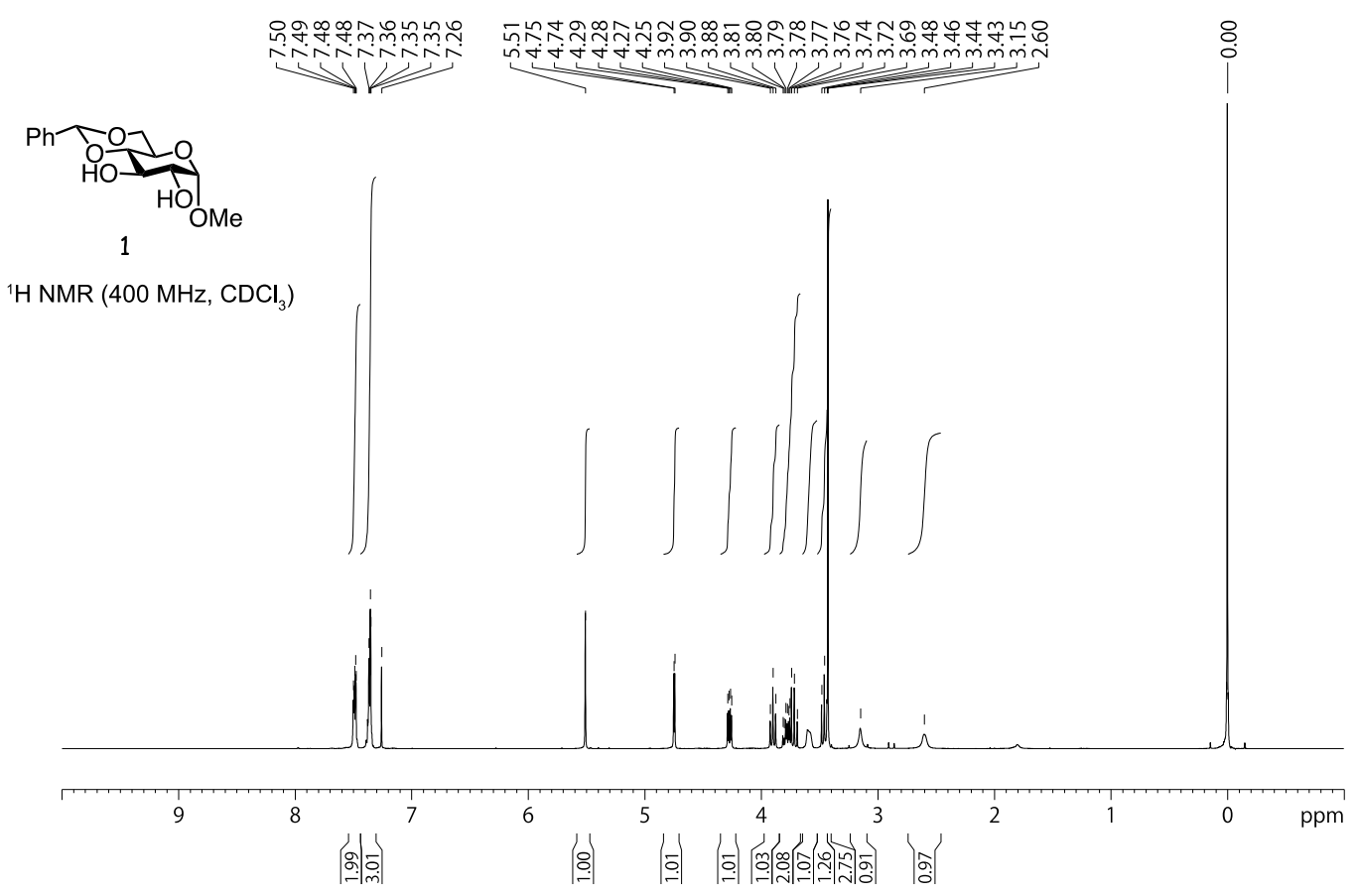

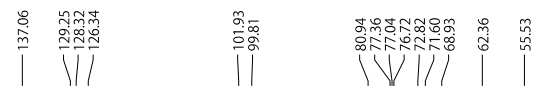

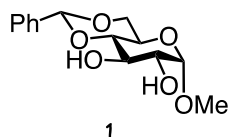

1

${ }^{13} \mathrm{C}$ NMR $\left(100 \mathrm{MHz}, \mathrm{CDCl}_{3}\right)$

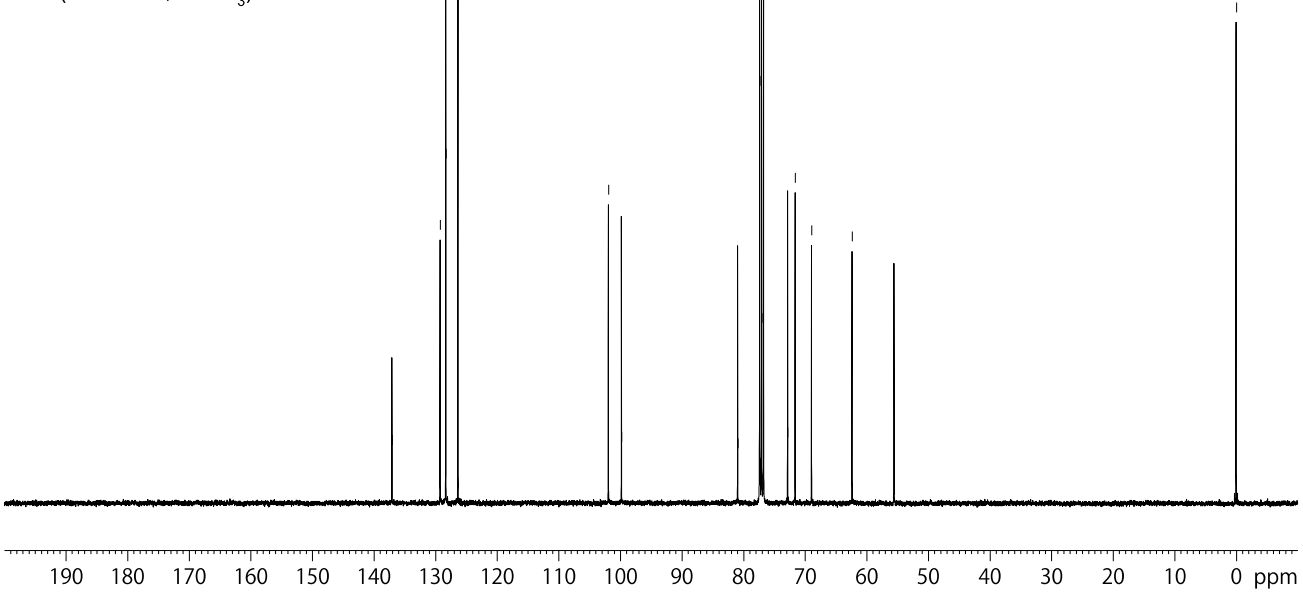


$2.2{ }^{1} \mathrm{H},{ }^{13} \mathrm{C}$ NMR spectra of compound 2

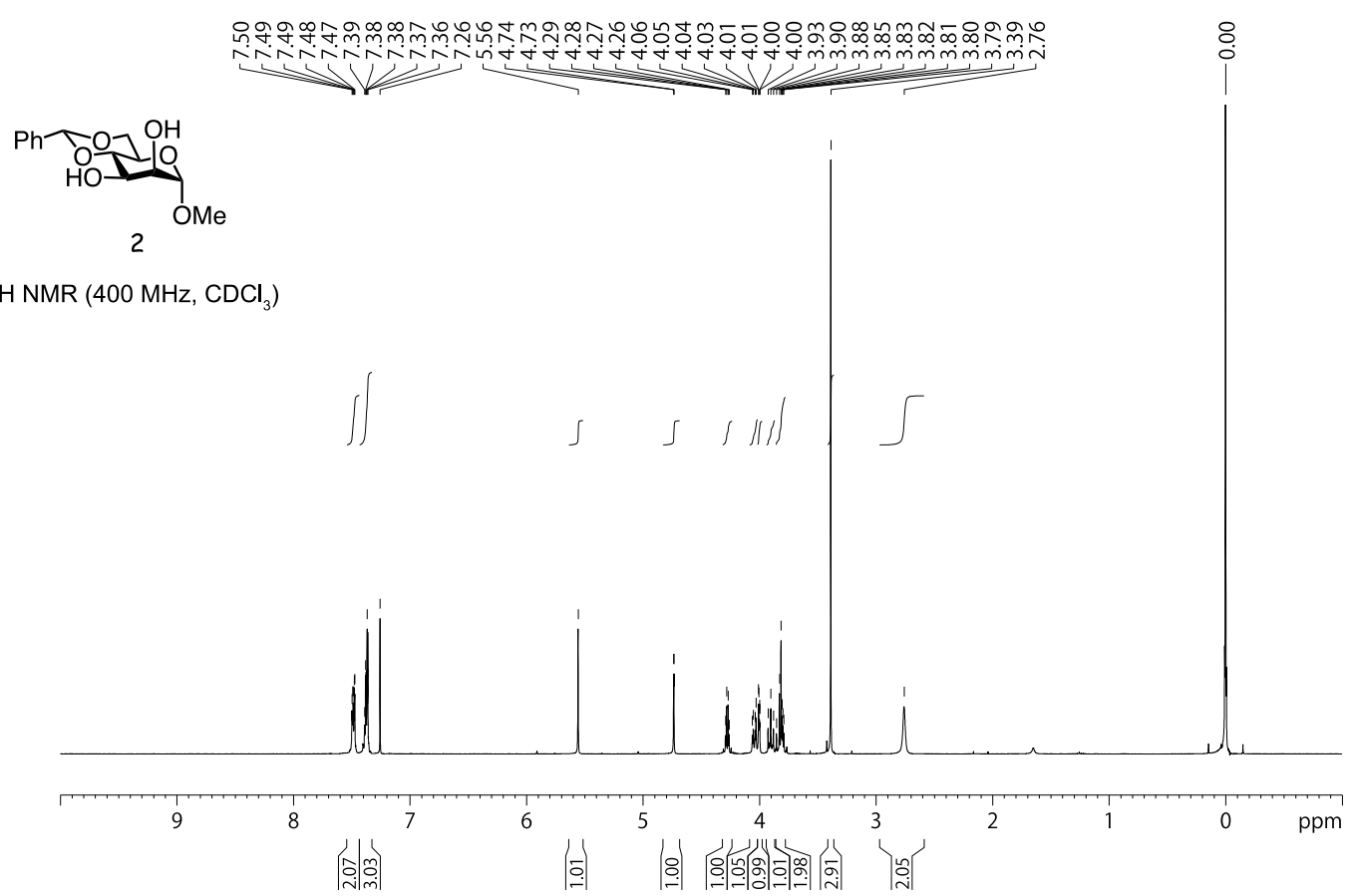

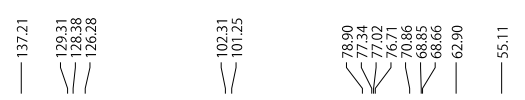

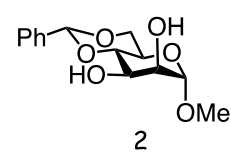

${ }^{13} \mathrm{C}$ NMR $\left(100 \mathrm{MHz}, \mathrm{CDCl}_{3}\right)$

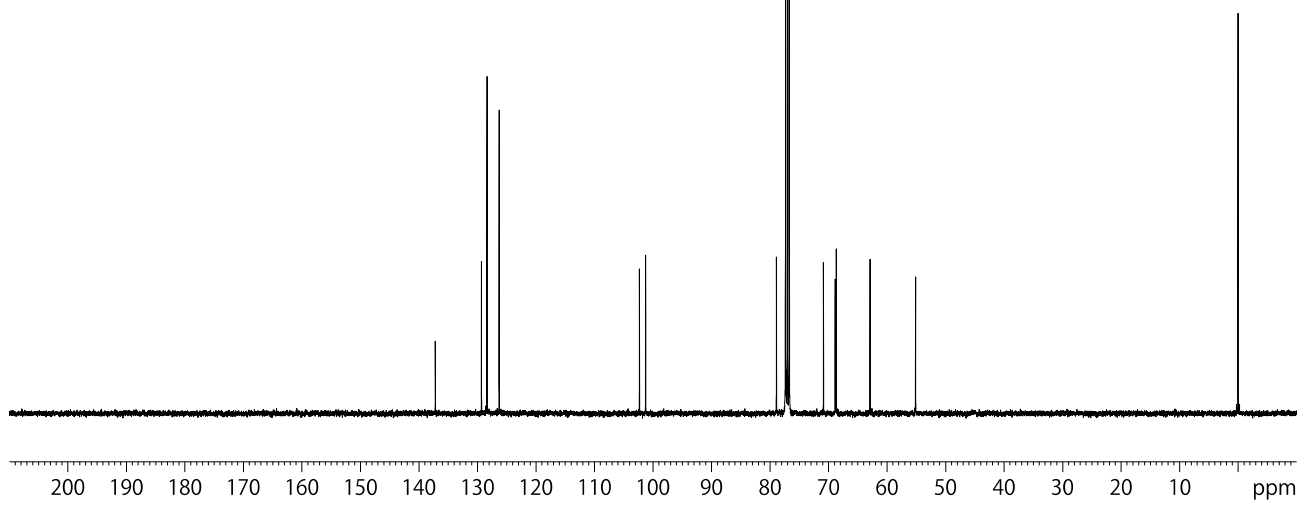


$2.3{ }^{1} \mathrm{H},{ }^{13} \mathrm{C}$ NMR spectra of compound 3
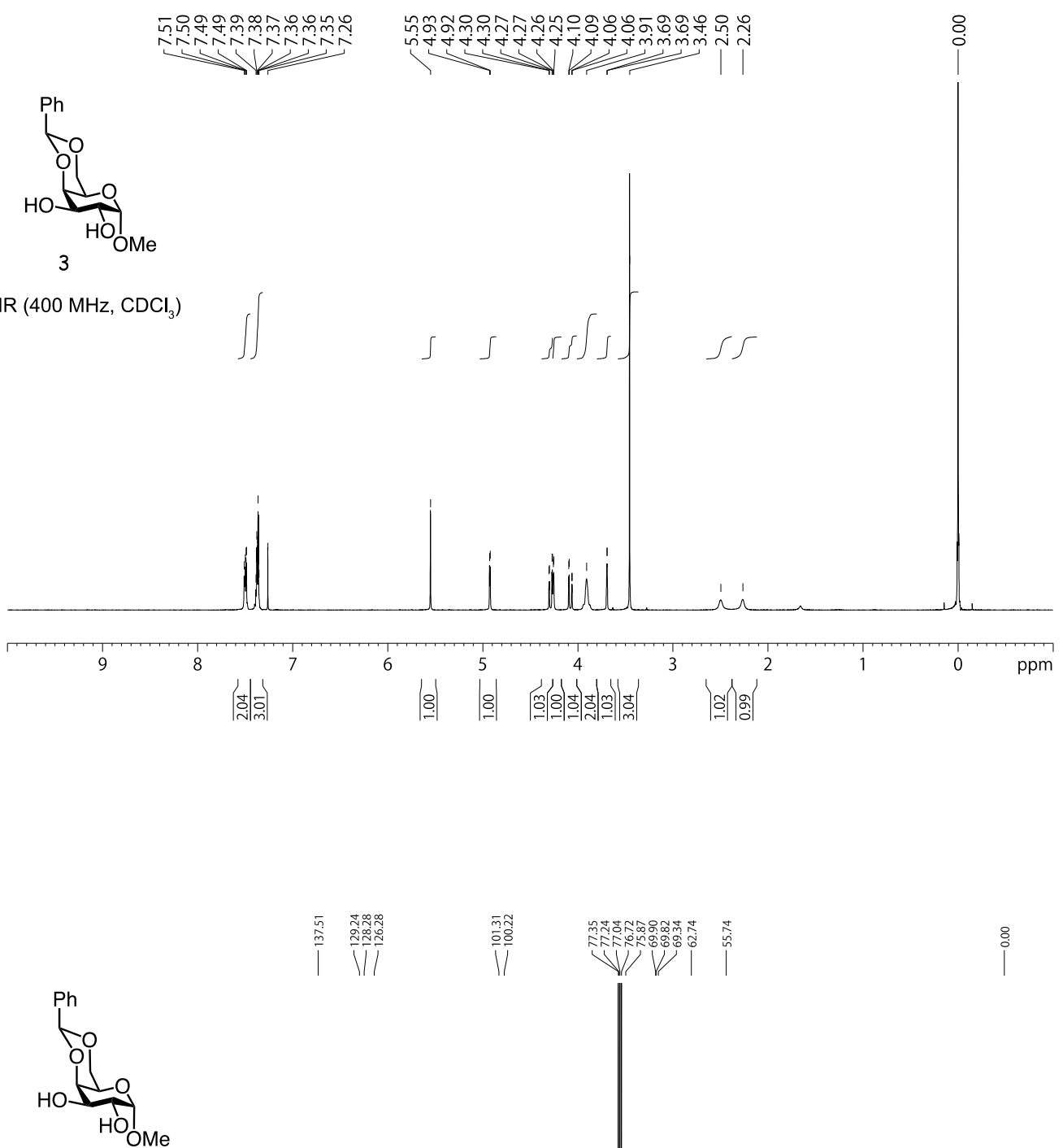

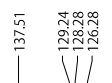

ำ

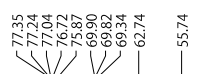

${ }^{13} \mathrm{C}$ NMR $\left(100 \mathrm{MHz}, \mathrm{CDCl}_{3}\right.$ )

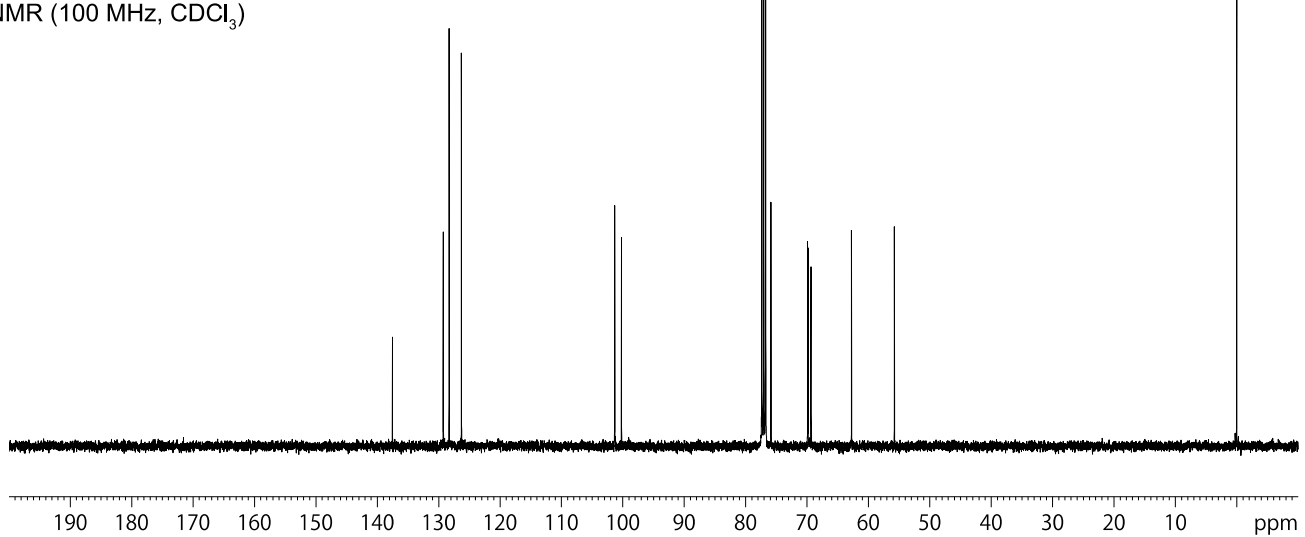


$2.4{ }^{1} \mathrm{H},{ }^{13} \mathrm{C}$ NMR spectra of compound 4
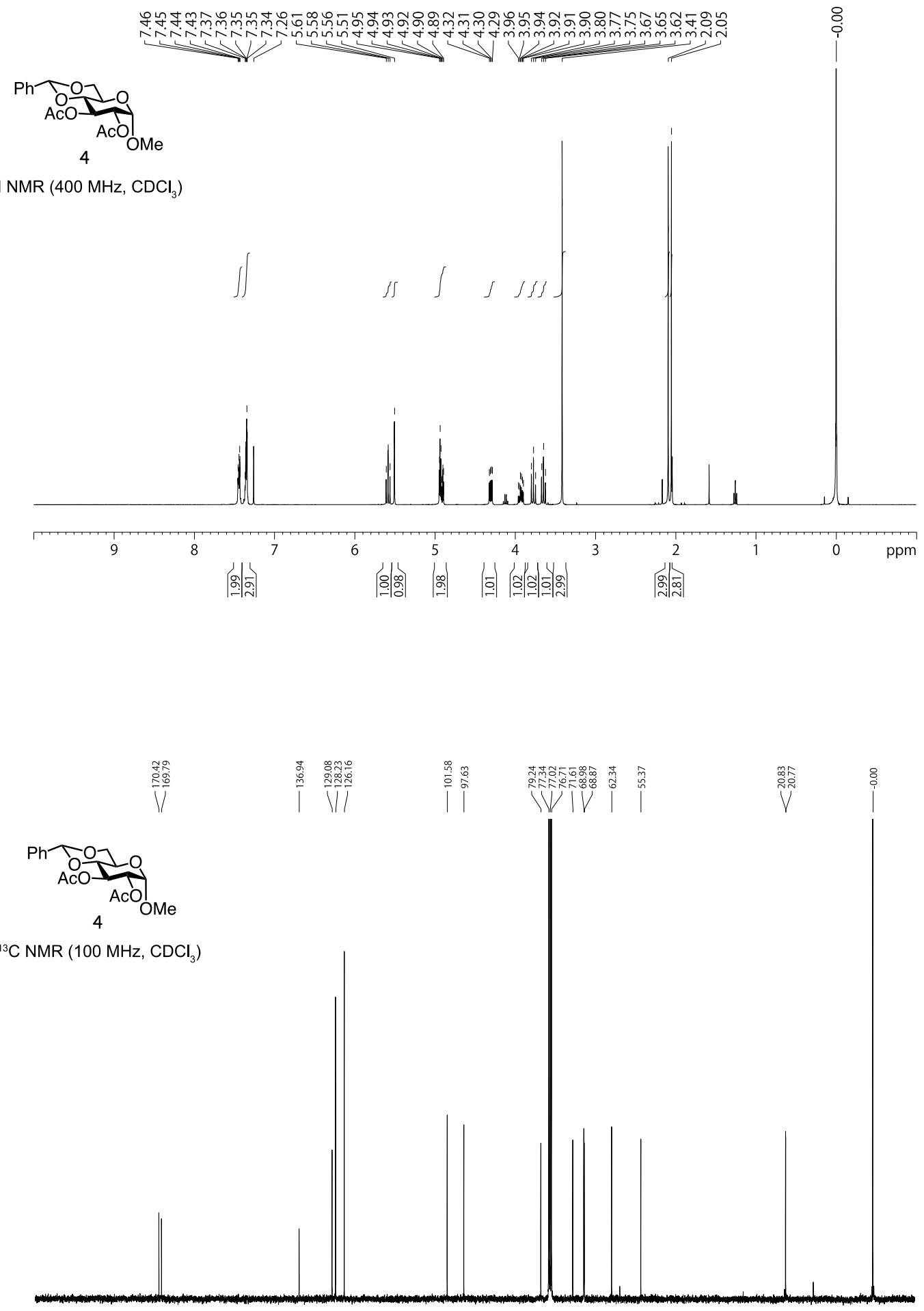

$\begin{array}{llllllllllllllllllllllllllllll}190 & 180 & 170 & 160 & 150 & 140 & 130 & 120 & 110 & 100 & 90 & 80 & 70 & 60 & 50 & 40 & 30 & 20 & 10 & \text { ppm }\end{array}$ 
$2.5{ }^{1} \mathrm{H},{ }^{13} \mathrm{C}$ NMR spectra of compound 5
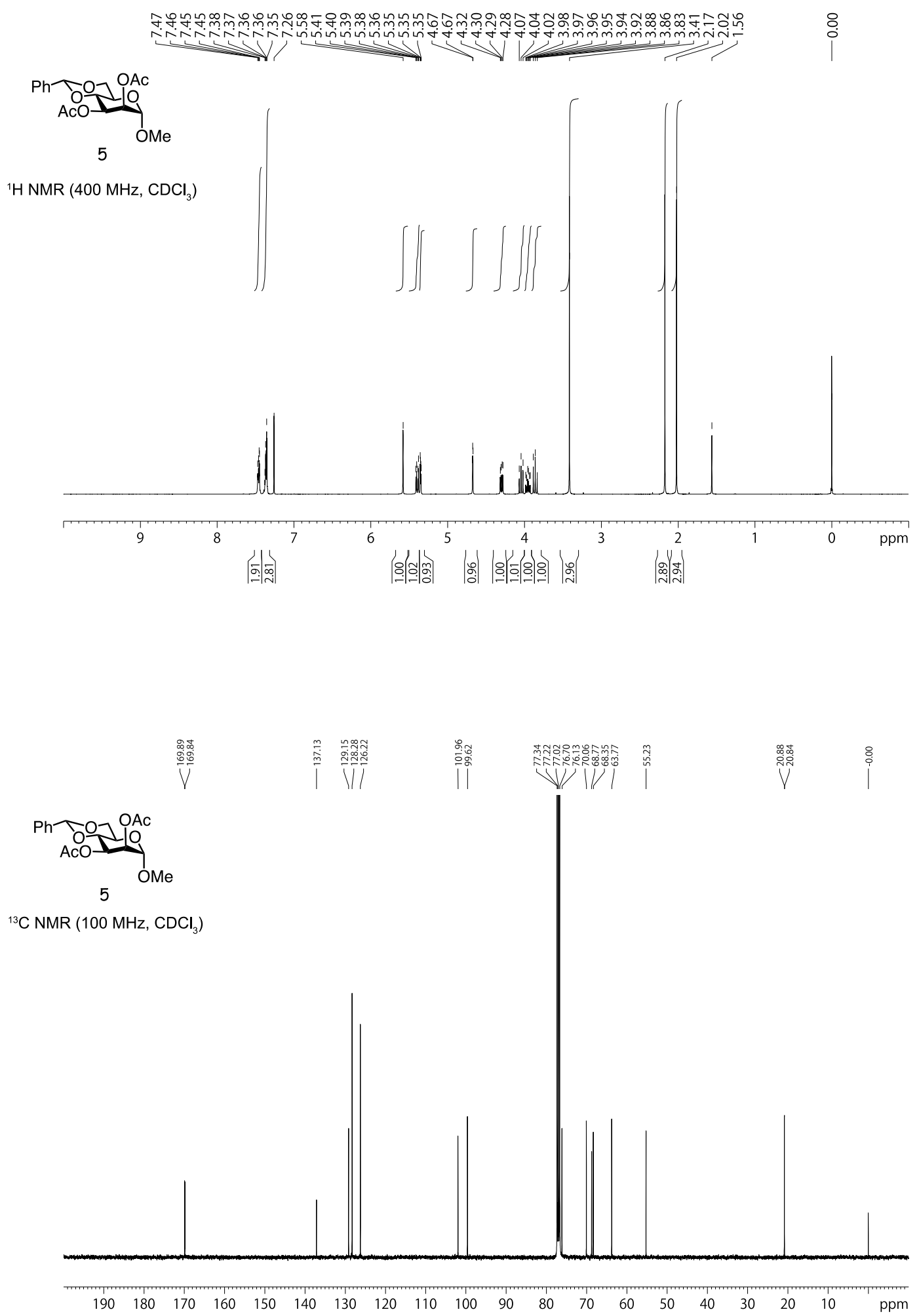
$2.6{ }^{1} \mathrm{H},{ }^{13} \mathrm{C}$ NMR spectra of compound 6
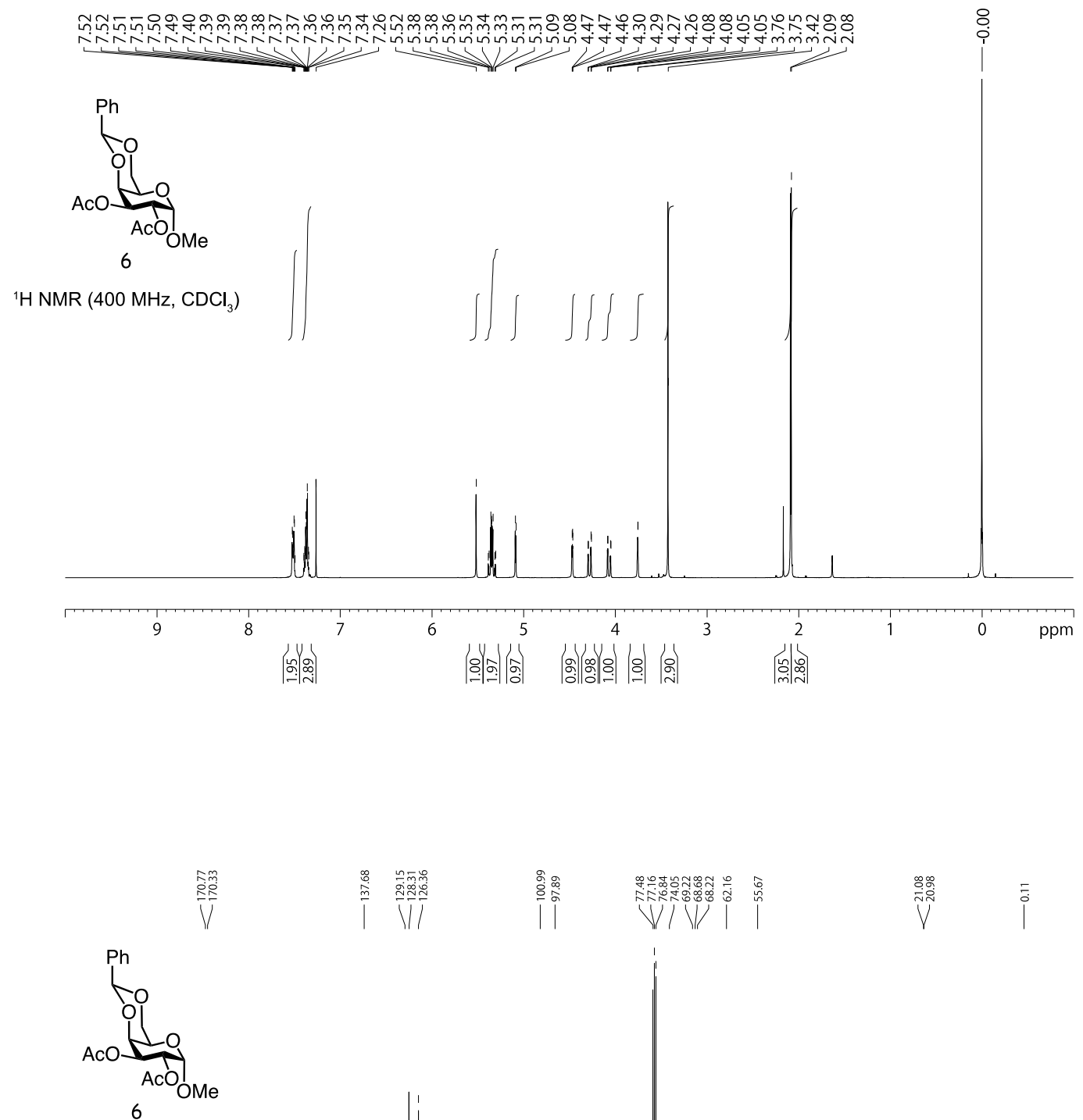

${ }^{13} \mathrm{C} \mathrm{NMR}\left(100 \mathrm{MHz}, \mathrm{CDCl}_{3}\right)$
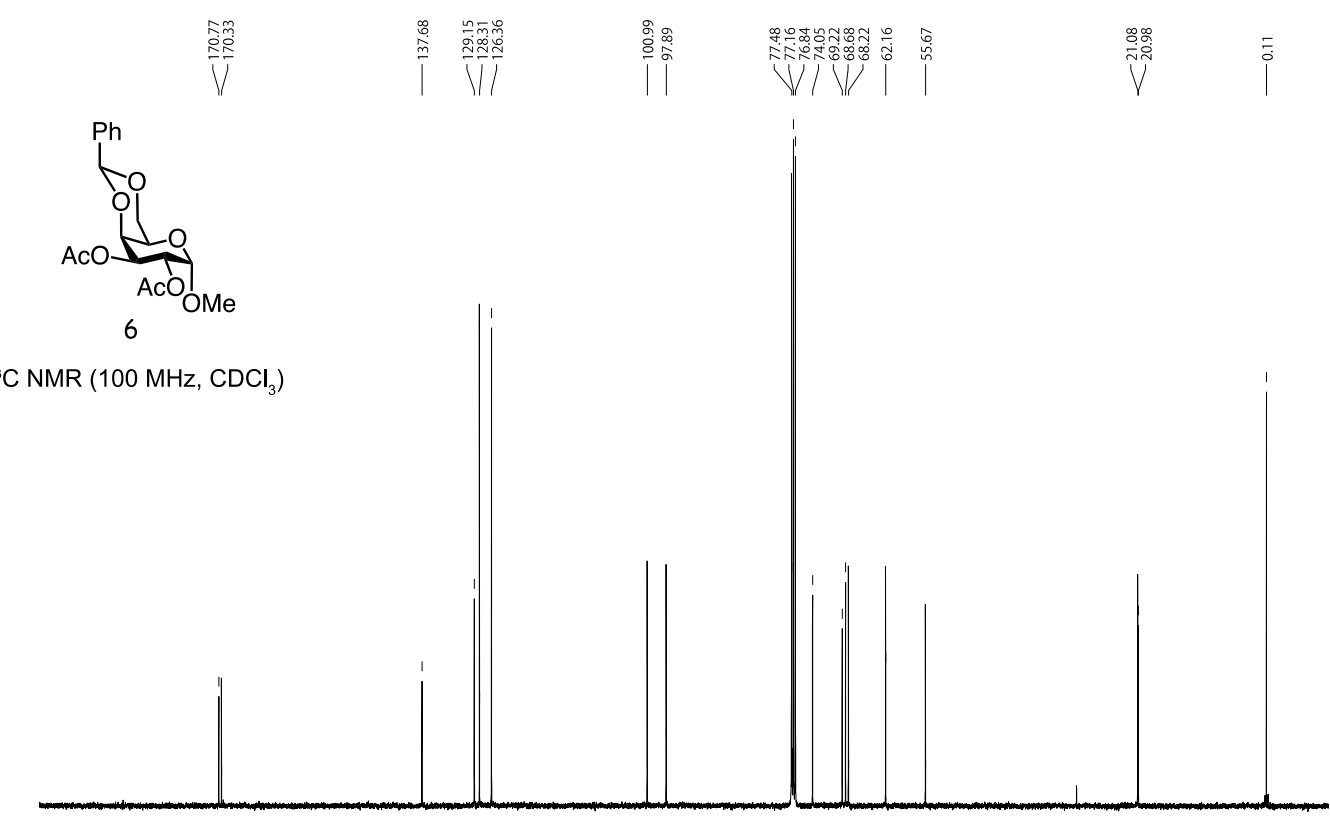

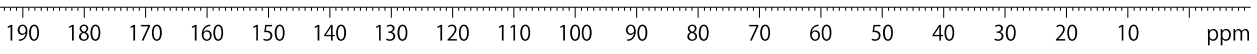

